\title{
An efficient finite element model for static and dynamic analyses of functionally graded piezoelectric beams
}

\author{
M. Lezgy-Nazargah ${ }^{a}$, P. Vidal ${ }^{\mathrm{b}, *}$, O. Polit ${ }^{\mathrm{b}}$ \\ ${ }^{a}$ Faculty of Civil Engineering, Hakim Sabzevari University, Sabzevar, Iran \\ ${ }^{\mathrm{b}}$ LEME - EA 4416, Université Paris Ouest, 50 rue de Sèvres, 92410 Ville d'Avray, France
}

\section{A B S T R A C T}

This study deals with static, free vibration and dynamic response of functionally graded piezoelectric material (FGPM) beams using an efficient three-nodded beam element. This beam finite element is based on a refined sinus model. It does not require shear correction factor and ensures continuity conditions for displacements, transverse shear stresses as well as boundary conditions on the upper and lower surfaces of the FGPM beam. This conforming finite element does not suffer from shear locking. The number of the mechanical unknowns is independent of the number of layers. A high-order electrical potential field is considered through each graded piezoelectric layer. The proposed FE is validated through static, free vibration and dynamic tests for FGPM beams. For various electrical and mechanical boundary conditions, excellent agreement is found between the results obtained from the proposed formulation and reference results from open literature or 3D FEM.

\section{Introduction}

It is well known that piezoelectric materials have been widely used as sensors and actuators in control systems due to their excellent electro-mechanical properties, easy fabrication, design flexibility, and efficiency to convert electrical energy into mechanical energy. Extensive studies have been carried out, and many theoretical and mathematical models have been presented for laminated composite structures with piezoelectric sensors and actuators until now [110,37]. Traditional piezoelectric sensors and actuators are often made of several layers of different piezoelectric materials. In these sandwich devices, adhesive epoxy resin is usually used to bond the piezoelectric layers, which causes some problems to arise. The principal weakness of these structures is that the high stress concentrations are usually appeared at the layer interfaces under mechanical or electrical loading. These stress concentrations lead to the initiation and propagation of micro-cracks near the interfaces of two bonded piezoelectric layers. This drawback restricts the usefulness of piezoelectric devices in the areas where the devices require high reliability.

In order to overcome these disadvantages, FGPM sensors and actuators were introduced and fabricated by Zhu and Meng [11], and $\mathrm{Wu}$ et al. [12]. FGPMs are a kind of piezoelectric materials whose mechanical and electrical properties vary continuously in one or more directions. FGPM actuators can produce not only large displacements but also reduce the internal stress concentrations

\footnotetext{
* Corresponding author. Tel.: +33 140974855.

E-mail addresses: m.lezgy@hsu.ac.ir (M. Lezgy-Nazargah), philippe.vidal@uparis10.fr (P. Vidal), olivier.polit@u-paris10.fr (O. Polit).
}

and consequently improve significantly the lifetime of piezoelectric actuators. Takagi et al [40] used a mixture system of PZT and Pt for the fabrication of FGPM bimorph actuators. To this end, they mixed the PZT and Pt powders together. The Pt contents of the powder mixtures were $0,10,20$ and $30 \mathrm{vol} \%$ for the graded layers and the electrode layer. The mixtures were stacked layer by layer into a steel die according to the lamination scheme [PZT, PZT/ $10 \% \mathrm{Pt}, \mathrm{PZT} / 20 \% \mathrm{Pt}, \mathrm{PZT} / 30 \% \mathrm{Pt}] \mathrm{S}$, then pressed. The formed specimens were cut to beams with dimensions $12 \times 2 \times 3 \mathrm{~mm}^{2}$. Nowadays, the FGPMs, as intelligent materials, have been used extensively in applications of sensors and actuators in the microelectro-mechanical system and smart structures.

A considerable number of papers involving the behavior of FGPMs already exists. Lim and He [13] obtained an exact solution for a compositionally graded piezoelectric layer under uniform stretch, bending and twisting load. Reddy and Cheng [14] obtained a 3D solution for smart FGPM plates. Zhong and Shang [15] presented an exact 3D solution for FGPM rectangular plates, by means of the state space approach. Lu et al. [16] obtained an exact solution for simply supported FGPM laminates in cylindrical bending by Stroh-like formalism. Using this method, Lu et al. [17] also proposed exact solutions for simply supported FGPM plates. Liu and Shi [18], and Shi and Chen [19] obtained closed form solutions for the FGPM cantilever beams using the two-dimensional (2D) theory of elasticity and the Airy stress function. Xiang and Shi [20] investigated thermo-electro-elastic response of a FGPM sandwich cantilever beam. They also employed the Airy stress function in order to study the effect of parameters such as the electromechanical coupling, functionally graded index, temperature change and thickness ratio on the static 
behavior of actuators/sensors. Using the so called state-space based differential quadrature method (SSDQM), Yang and Zhifei [21] investigated the free vibration of a FGPM beam.

The beam and plate/shell theories have been presented for the structural analysis of FGPM structures in the literature. But, in most of the available beam and plate/shell models, it is assumed that the functionally graded piezoelectric layer consists of a number of laminates, where the material properties within each laminate are invariant. Liu and Tani [22] used this method to study the wave propagation in FGPM plates. Chen and Ding [23] analyzed the free vibration of FGPM rectangular plates using the aforementioned method. Lee [24] used a layerwise finite element formulation to investigate the displacement and stress response of a FGPM bimorph actuator. Such models are sufficiently accurate but it needs a high computational cost. By using the Timoshenko beam theory, Yang and Xiang [25] investigated the static and dynamic response of FGPM actuators under thermo-electro-mechanical loadings. In their work, the numerical results were obtained by using the differential quadrature method (DQM). A comprehensive study on the static, dynamic and free vibration response of FGPM panels under different sets of mechanical, thermal and electrical loadings using the finite element method was presented by Behjat et al. [26]. Behjat et al. [27] investigated also the static bending, free vibration and dynamic response of FGPM plates under mechanical and electrical loading using the first order shear deformation theory. Doroushi et al. [28] studied free and forced vibration characteristics of a FGPM beam under thermoelectro-mechanical loads using third-order shear deformation beam theory. Wu et al. [29] derived a high-order theory for FGPM shells based on the generalized Hamilton's principle.

In this paper, a refined Sinus beam finite element is evaluated for static bending, free vibration and transient dynamic response of FGPM beams. This element is based on the Sinus model introduced in Touratier [30]. Then, it has been extended to take into account the interlaminar continuity of the transverse shear stresses in Polit and Touratier [31] for plates, and in Dau et al. [32] for shells. The coupling with the piezoelectric effect is carried out in Ossadzow-David and Touratier [33] and Fernandes and Pouget [34] using an analytical approach. The original Sinus model has been enriched in Vidal and Polit [35] by introducing a layer refinement in the kinematics, and then extended to thermal effects (Vidal and Polit [36]). In the present study, it is intended to extend these last works to static and dynamic analyses of FGPM beams.

The proposed beam element is a three-nodded element which satisfies the continuity conditions between layers of laminates for displacements, transverse shear stress and the free conditions at the top and bottom surfaces of the beam. The element is totally free of shear locking. It has four independent generalized displacements. Concerning the electrical part, a high-order electrical potential field is considered. In contrast with many of the available studies on FGPMs, which consider one of the graded piezoelectric properties variable in the thickness direction, here it is assumed that all material properties are variable in the thickness of the beam. The results obtained from the present finite element model are in good agreement with previous published and coupled finite element (ABAQUS) reference solutions. Moreover, the computational cost of the present element is very low in comparison with the available layer-wise beam and plate/shell theories.

\section{Formulation of the piezoelectric problem}

\subsection{Geometry, coordinate system}

The laminated beam has a rectangular uniform cross section of length $L$, width $b$, height $h$, and is made of $N_{l}$ layers either completely or in part constituted of FGPMs. The geometric parameters and the chosen Cartesian coordinate system $\left(x_{1}, x_{2}, x_{3}\right)$ are shown in Fig. 1.

\subsection{Constitutive equations}

The 3D linear constitutive equations of the $k$ th layer, polarized along its thickness direction in its global material coordinate system can be expressed as:

$$
\begin{aligned}
& \left\{\begin{array}{l}
\sigma_{11} \\
\sigma_{22} \\
\sigma_{33} \\
\sigma_{23} \\
\sigma_{13} \\
\sigma_{12}
\end{array}\right\}=\left[\begin{array}{cccccc}
c_{11} & c_{12} & c_{13} & 0 & 0 & c_{16} \\
c_{12} & c_{22} & c_{23} & 0 & 0 & c_{26} \\
c_{13} & c_{23} & c_{33} & 0 & 0 & c_{36} \\
0 & 0 & 0 & c_{44} & c_{45} & 0 \\
0 & 0 & 0 & c_{45} & c_{55} & 0 \\
c_{16} & c_{26} & c_{36} & 0 & 0 & c_{66}
\end{array}\right]^{(k)}\left\{\begin{array}{c}
\varepsilon_{11} \\
\varepsilon_{22} \\
\varepsilon_{33} \\
2 \varepsilon_{23} \\
2 \varepsilon_{13} \\
2 \varepsilon_{12}
\end{array}\right\} \\
& -\left[\begin{array}{ccc}
0 & 0 & e_{31} \\
0 & 0 & e_{32} \\
0 & 0 & e_{33} \\
e_{14} & e_{24} & 0 \\
e_{15} & e_{25} & 0 \\
0 & 0 & e_{36}
\end{array}\right]^{(k)} \quad\left\{\begin{array}{l}
E_{1} \\
E_{2} \\
E_{3}
\end{array}\right\} \\
& \begin{aligned}
\left\{\begin{array}{l}
D_{1} \\
D_{2} \\
D_{3}
\end{array}\right\}= & {\left[\begin{array}{cccccc}
0 & 0 & 0 & e_{14} & e_{15} & 0 \\
0 & 0 & 0 & e_{24} & e_{25} & 0 \\
e_{31} & e_{32} & e_{33} & 0 & 0 & e_{36}
\end{array}\right]^{(k)}\left\{\begin{array}{c}
\varepsilon_{11} \\
\varepsilon_{22} \\
\varepsilon_{33} \\
2 \varepsilon_{23} \\
2 \varepsilon_{13} \\
2 \varepsilon_{12}
\end{array}\right\} } \\
& +\left[\begin{array}{ccc}
\chi_{11} & \chi_{12} & 0 \\
\chi_{12} & \chi_{22} & 0 \\
0 & 0 & \chi_{33}
\end{array}\right]^{(k)}\left\{\begin{array}{l}
E_{1} \\
E_{2} \\
E_{3}
\end{array}\right\}
\end{aligned}
\end{aligned}
$$

where $\sigma_{i j}, \varepsilon_{i j}$ and $E_{i}$ denote the stress tensor, the infinitesimal strain tensor and the electric field components respectively. $D_{i}$ is the electric displacement vector components, and $c_{k l}, e_{i k}, \chi_{i j}$ the elastic, piezoelectric and dielectric material constants. Unlike the homogeneous piezoelectric materials $c_{k l}, e_{i k}$ and $\chi_{i j}$ are now functions depending on the coordinate $x_{3}$. In the present study, it is assumed that the material properties have the following arbitrary distributions along the thickness direction:

$c_{k l}=c_{k l}^{0} f\left(x_{3}\right), \quad e_{i k}=e_{i k}^{0} f\left(x_{3}\right), \quad \chi_{i j}=\chi_{i j}^{0} f\left(x_{3}\right)$

$i, j=1,2,3 \quad k, l=1,2, \ldots, 6$

$f\left(x_{3}\right)$ is an arbitrary function, and $c_{k l}^{0}, e_{i k}^{0}$ and $\chi_{i j}^{0}$ are the values of material properties at the plane $x_{3}=0$.

In a FGPM beam, the constitutive relations (1) and (2) reduce to:

$$
\begin{aligned}
\overline{\boldsymbol{\sigma}} & =\overline{\boldsymbol{C}} \overline{\boldsymbol{\varepsilon}}-\overline{\boldsymbol{e}} \overline{\boldsymbol{E}} \\
\overline{\boldsymbol{D}} & =\overline{\boldsymbol{e}}^{T} \overline{\boldsymbol{\varepsilon}}+\bar{\chi} \overline{\boldsymbol{E}}
\end{aligned}
$$

where

$$
\overline{\boldsymbol{\sigma}}=\left[\begin{array}{l}
\sigma_{11} \\
\sigma_{13}
\end{array}\right], \quad \overline{\mathbf{D}}=\left[\begin{array}{l}
D_{1} \\
D_{3}
\end{array}\right]
$$$$
\overline{\boldsymbol{C}}=\left[\begin{array}{cc}
c_{11} & 0 \\
0 & c_{55}
\end{array}\right]-\left[\begin{array}{cccc}
c_{12} & c_{13} & c_{16} & 0 \\
0 & 0 & 0 & c_{54}
\end{array}\right]\left[\begin{array}{cccc}
c_{22} & c_{23} & c_{26} & 0 \\
c_{32} & c_{33} & c_{36} & 0 \\
c_{62} & c_{63} & c_{66} & 0 \\
0 & 0 & 0 & c_{44}
\end{array}\right]^{-1}\left[\begin{array}{cc}
c_{21} & 0 \\
c_{31} & 0 \\
c_{61} & 0 \\
0 & c_{45}
\end{array}\right]
$$

$$
\overline{\boldsymbol{e}}=\left[\begin{array}{ll}
e_{11} & e_{31} \\
e_{15} & e_{35}
\end{array}\right]-\left[\begin{array}{cccc}
c_{12} & c_{13} & c_{16} & 0 \\
0 & 0 & 0 & c_{54}
\end{array}\right]\left[\begin{array}{cccc}
c_{22} & c_{23} & c_{26} & 0 \\
c_{32} & c_{33} & c_{36} & 0 \\
c_{62} & c_{63} & c_{66} & 0 \\
0 & 0 & 0 & c_{44}
\end{array}\right]^{-1}\left[\begin{array}{ll}
e_{12} & e_{32} \\
e_{13} & e_{33} \\
e_{16} & e_{36} \\
e_{14} & e_{34}
\end{array}\right]
$$




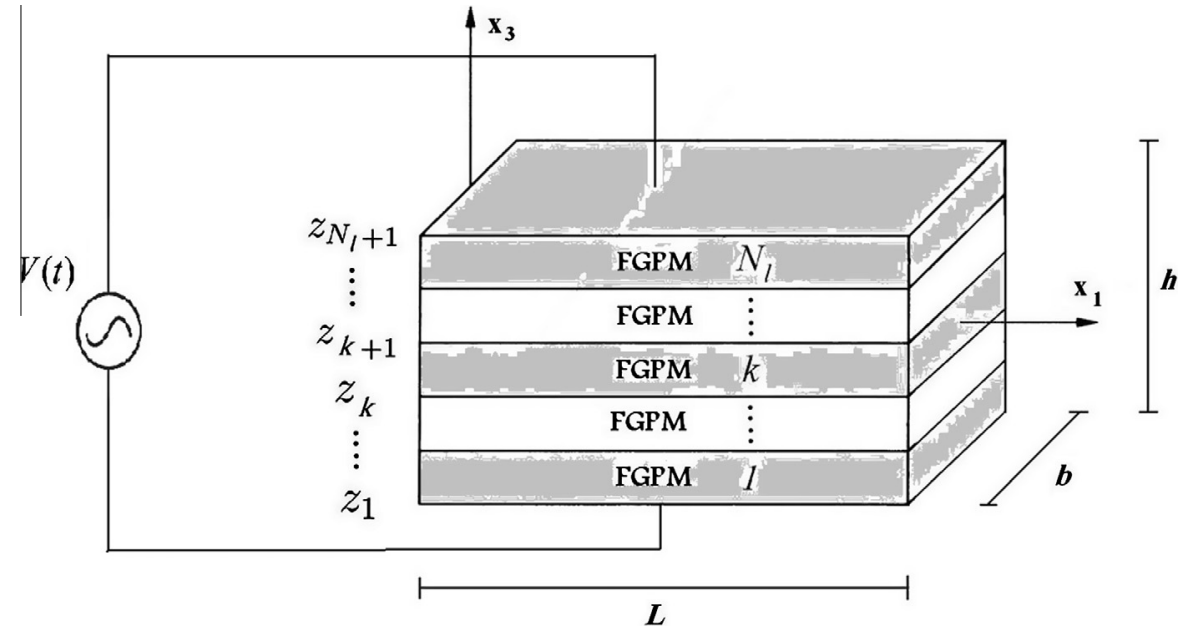

Fig. 1. FGPM beam: Cartesian coordinate system and geometric parameters.

$\overline{\boldsymbol{\chi}}=\left[\begin{array}{ll}\chi_{11} & \chi_{13} \\ \chi_{31} & \chi_{33}\end{array}\right]+\left[\begin{array}{llll}e_{12} & e_{13} & e_{16} & e_{14} \\ e_{32} & e_{33} & e_{36} & e_{34}\end{array}\right]\left[\begin{array}{cccc}c_{22} & c_{23} & c_{26} & 0 \\ c_{32} & c_{33} & c_{36} & 0 \\ c_{62} & c_{63} & c_{66} & 0 \\ 0 & 0 & 0 & c_{44}\end{array}\right]^{-1}\left[\begin{array}{ll}e_{12} & e_{32} \\ e_{13} & e_{33} \\ e_{16} & e_{36} \\ e_{14} & e_{34}\end{array}\right]$

\subsection{Weak formulation}

The principle of virtual work for the piezoelectric medium of volume $\Omega$ and regular boundary surface $\Gamma$ can be written as:

$$
\begin{aligned}
\delta \Pi= & \delta U-\delta W \\
= & -\int_{\Omega} \delta \boldsymbol{\varepsilon}^{T} \boldsymbol{\sigma} d \Omega+\int_{\Gamma} \delta \boldsymbol{u}^{T} \boldsymbol{F}_{S} d \Gamma+\int_{\Omega} \delta \boldsymbol{u}^{T} \boldsymbol{F}_{V} d \Omega-\int_{\Omega} \rho \delta \boldsymbol{u}^{T} \ddot{\boldsymbol{u}} d \Omega \\
& +\int_{\Omega} \delta \boldsymbol{E}^{T} \boldsymbol{D} d \Omega-\int_{\Gamma} \bar{Q} \delta \boldsymbol{\varphi} d \Gamma-\int_{\Omega} \bar{q} \delta \boldsymbol{\varphi} d \Omega=0
\end{aligned}
$$

where $\boldsymbol{F}_{S}, \boldsymbol{F}_{\boldsymbol{V}}, \bar{q}, \bar{Q}$ and $\rho$ are surface force vector, mechanical body force vector, electrical body charge, surface charge and mass density, respectively. $\delta \boldsymbol{u}$ and $\delta \boldsymbol{\varphi}$ are admissible virtual displacement and potential.

\subsection{Displacement and strain fields}

The displacement field used in the present study is given by Vidal and Polit [35]:

$$
\begin{aligned}
u_{1}\left(x_{1}, x_{2}, x_{3}, t\right)= & u\left(x_{1}, t\right)-x_{3} w\left(x_{1}, t\right)_{, 1}+\left(\omega_{3}\left(x_{1}, t\right)+w\left(x_{1}, t\right)_{, 1}\right) F\left(x_{3}\right) \\
& +S\left(x_{3}\right) u_{31}^{1}\left(x_{1}, t\right) \\
u_{3}\left(x_{1}, x_{2}, x_{3}, t\right)= & w\left(x_{1}, t\right)
\end{aligned}
$$

where the functions $u_{1}\left(x_{1}, x_{2}, x_{3}, t\right)$ and $u_{3}\left(x_{1}, x_{2}, x_{3}, t\right)$ represent the axial and transverse displacement components, respectively. $u\left(x_{1}, t\right)$ and $w\left(x_{1}, t\right)$ are the displacement components of the central line. $t$ is the time and $\omega_{3}\left(x_{1}, t\right)$ denotes the shear-bending rotation around the $x_{2}$ axis. $u_{31}^{1}\left(x_{1}, t\right)$ is a supplementary unknown function associated with the refinement per layer. In the context of the refined sinus model, we also have:

$$
\begin{aligned}
F\left(x_{3}\right)= & \left.\frac{h}{\pi} \sin \left(\frac{\pi x_{3}}{h}\right)+\sum_{k=1}^{N C} \xi_{k} \beta_{1}^{k}+-\frac{1}{2}+\frac{3 \xi_{k}^{2}}{2}\right) \beta_{2}^{k} \\
& \left.\left.+-\frac{3 \xi_{k}}{2}+\frac{5 \xi_{k}^{3}}{2}\right) \beta_{3}^{k}\right)\left(H\left(x_{3}-z_{k}\right)-H\left(x_{3}-z_{k+1}\right)\right)
\end{aligned}
$$

$$
\begin{aligned}
S\left(x_{3}\right)= & \left.\left.\sum_{k=1}^{N C}\left(\xi_{k} \delta_{1}^{k}+-\frac{1}{2}+\frac{3 \xi_{k}^{2}}{2}\right) \delta_{2}^{k}+-\frac{3 \xi_{k}}{2}+\frac{5 \xi_{k}^{3}}{2}\right) \delta_{3}^{k}\right) \\
& \left(H\left(x_{3}-z_{k}\right)-H\left(x_{3}-z_{k+1}\right)\right)
\end{aligned}
$$

where $\xi_{k}=a_{k} x_{3}-b_{k}, a_{k}=\frac{2}{z_{k+1}-z_{k}}, b_{k}=\frac{z_{k+1}+z_{k}}{z_{k+1}-z_{k}}$ with $x_{3} \in\left[z_{k} ; z_{k+1}\right]$.

In the above equations, $H$ is the Heaviside's function. $\beta_{1}^{k}, \beta_{2}^{k}, \beta_{3}^{k}, \delta_{1}^{k}, \delta_{2}^{k}$ and $\delta_{3}^{k}$ are coefficients deduced from the inter-laminar continuity conditions of the transverse shear stress on the interfaces between the layers, and the boundary conditions on the upper and lower surfaces of the beam. It is worthy to note that these coefficients depend on the material properties and the global coordinates of the layers. It is seen from Eqs. (6) and (7) that the refined sinus model includes only four mechanical generalized unknowns $u, w, \omega_{3}$ and $u_{31}^{1}$. For further details on the formulations, the interested readers can refer to [34].

The strain equations can be derived from the displacement field:

$\varepsilon_{11}=u_{, 1}-\left(x_{3}\right) w_{, 11}+\left(\omega_{3,1}+w_{, 11}\right) F\left(x_{3}\right)+S\left(x_{3}\right) u_{31,1}^{1}$

$\gamma_{13}=\left(\omega_{3}+w_{, 1}\right) F\left(x_{3}\right)_{, 3}+S\left(x_{3}\right)_{, 3} u_{31}^{1}$

\subsection{High-order electric potential}

In this study the following high-order electric potential has been used for the $k$ th functionally graded piezoelectric layer:

$$
\begin{aligned}
\phi^{k}\left(x_{1}, x_{2}, \xi_{k}\right)= & L_{k 1}\left(\xi_{k}\right) \phi_{b}^{k}\left(x_{1}, x_{2}\right)+L_{k 2}\left(\xi_{k}\right) \bar{E}_{b}^{k}\left(x_{1}, x_{2}\right) \\
& +L_{k 3}\left(\xi_{k}\right) \phi_{t}^{k}\left(x_{1}, x_{2}\right)+L_{k 4}\left(\xi_{k}\right) \bar{E}_{t}^{k}\left(x_{1}, x_{2}\right)
\end{aligned}
$$

where $\bar{E}_{t}^{k}\left(x_{1}, x_{2}\right)$ and $\bar{E}_{b}^{k}\left(x_{1}, x_{2}\right)$ denote the electric field at the top and bottom surfaces, respectively. $\phi_{t}^{k}\left(x_{1}, x_{2}\right)$ and $\phi_{b}^{k}\left(x_{1}, x_{2}\right)$ are the electric potential at the top and bottom surfaces of the graded piezoelectric layer. $L_{k i}\left(\xi_{k}\right) \quad(i=1,2,3,4)$ are the interpolation functions as follows:

$$
\begin{array}{ll}
L_{k 1}=\frac{1}{4}\left(1-\xi_{k}\right)^{2}\left(2+\xi_{k}\right), & L_{k 2}=\frac{\left(z_{k+1}-z_{k}\right)}{8}\left(1-\xi_{k}\right)^{2}\left(1+\xi_{k}\right) \\
L_{k 3}=\frac{1}{4}\left(2-\xi_{k}\right)\left(1+\xi_{k}\right)^{2}, & L_{k 4}=-\frac{\left(z_{k+1}-z_{k}\right)}{8}\left(1-\xi_{k}\right)\left(1+\xi_{k}\right)^{2}
\end{array}
$$




$$
\begin{aligned}
\boldsymbol{E}_{k} & =\left[\begin{array}{l}
E_{1} \\
E_{3}
\end{array}\right]_{k}=-\left[\begin{array}{l}
\frac{\partial \phi}{\partial x_{1}} \\
\frac{\partial \phi}{\partial x_{3}}
\end{array}\right]_{k} \\
& =-\left[\begin{array}{cccc}
L_{k 1}\left(\xi_{k}\right) \frac{d}{d x_{1}} & L_{k 2}\left(\xi_{k}\right) \frac{d}{d x_{1}} & L_{k 3}\left(\xi_{k}\right) \frac{d}{d x_{1}} & L_{k 4}\left(\xi_{k}\right) \frac{d}{d x_{1}} \\
\frac{d L_{k 1}}{d z} & \frac{d L_{k 2}}{d z} & \frac{d L_{k 3}}{d z} & \frac{d L_{k 4}}{d z}
\end{array}\right]\left[\begin{array}{l}
\phi_{b}^{k} \\
\bar{E}_{b}^{k} \\
\phi_{t}^{k} \\
\bar{E}_{t}^{k}
\end{array}\right]=-\boldsymbol{L}_{\phi}^{k} \boldsymbol{u}_{\phi}^{k}
\end{aligned}
$$

\section{Finite element formulation}

In this section, finite element approximations are defined for the mechanical and electrical variables of Eqs. (6), (8) and (11). As the highest derivative of $w$ in the expression of the strain energy is of second-order, this variable is interpolated using the $C^{1}$-continuous Hermite cubic shape functions. As far as the rotation $\omega_{3}$ is concerned, the quadratic Lagrangian shape functions are chosen. Furthermore, if an identical order is adopted for the shape functions of both $w_{0,1}$ and $\omega_{3}$ in the relevant transverse shear strain components, the shear locking phenomenon is avoided as the field compatibility condition is ensured [8,34]. $u_{0}$ and $u_{1}^{1}$ are also interpolated using Lagrangian quadratic shape functions. Finally, for the interpolation of the electrical variables $\phi_{b}^{i}, \bar{E}_{b}^{i}, \phi_{t}^{i}$ and $\bar{E}_{t}^{i}$, Lagrangian linear shape functions may be employed. The developed beam element has three nodes with a variable number of electric potential degrees of freedom at each node. Based on Eqs. (6), (8), (9) and (11), the electric potential, displacements, strain and electric field components may be expressed under the following matrices form:

$\left[\begin{array}{l}\boldsymbol{u} \\ \varphi\end{array}\right]=\left[\begin{array}{cc}\boldsymbol{A}_{u \boldsymbol{u}} & \mathbf{0} \\ \mathbf{0} & \boldsymbol{A}_{\varphi \varphi}\end{array}\right]\left[\begin{array}{l}\boldsymbol{u}_{u} \\ \boldsymbol{u}_{\varphi}\end{array}\right], \quad\left[\begin{array}{l}\boldsymbol{\varepsilon} \\ \boldsymbol{E}\end{array}\right]=\left[\begin{array}{cc}\boldsymbol{L}_{\boldsymbol{u} u} & \mathbf{0} \\ \mathbf{0} & \boldsymbol{L}_{\varphi \varphi}\end{array}\right]\left[\begin{array}{l}\boldsymbol{u}_{u} \\ \boldsymbol{u}_{\varphi}\end{array}\right]$

where $\quad \mathbf{u}=\left[\begin{array}{ll}u_{1} & u_{3}\end{array}\right]^{T}, \mathbf{u}_{u}=\left[\begin{array}{llll}u & w & \omega_{3} & u_{31}^{1}\end{array}\right]^{T}, \boldsymbol{\varphi}=\left[\phi^{i}\right]^{T}$, $\mathbf{u}_{\varphi}=\left[\begin{array}{llll}\phi_{b}^{i} & \bar{E}_{b}^{i} & \phi_{t}^{i} & \bar{E}_{t}^{i}\end{array}\right]^{T}, \boldsymbol{\varepsilon}=\left[\begin{array}{ll}\varepsilon_{11} & \gamma_{13}\end{array}\right]^{T}, \mathbf{E}=\left[\begin{array}{ll}E_{1} & E_{3}\end{array}\right]^{T}$. The vector of displacement and electric potential components $\boldsymbol{u}_{u}$ and $\boldsymbol{u}_{\varphi}$ may be expressed in terms of the mechanical and electrical dof vectors $\boldsymbol{u}_{u}^{e}$ and $\boldsymbol{u}_{\varphi}^{\mathbf{e}}$ as follows:

$\left[\begin{array}{l}\boldsymbol{u}_{u} \\ \boldsymbol{u}_{\varphi}\end{array}\right]=\left[\begin{array}{cc}\boldsymbol{N}_{u u} & \mathbf{0} \\ \mathbf{0} & \boldsymbol{N}_{\varphi \varphi}\end{array}\right]\left[\begin{array}{l}\boldsymbol{u}_{u}^{e} \\ \boldsymbol{u}_{\varphi}^{e}\end{array}\right]$

where

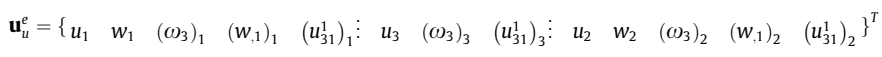

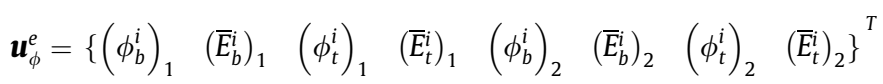

For the sake of brevity, the expression for $\mathbf{A}_{\mathbf{u u}}, \mathbf{A}_{\boldsymbol{\varphi} \varphi}, \mathbf{L}_{\mathbf{u u}}, \mathbf{L}_{\boldsymbol{\varphi} \varphi}, \mathbf{N}_{\boldsymbol{u} u}$ and $\boldsymbol{N}_{\boldsymbol{\varphi} \varphi}$ are not presented here. Using Eqs. (12) and (13), the displacements and electric potential vectors can be expressed as follows:

$\left[\begin{array}{l}\boldsymbol{u} \\ \boldsymbol{\varphi}\end{array}\right]=\mathcal{N} \boldsymbol{u}^{e}$

with

$\mathcal{N}=\left[\begin{array}{cc}\boldsymbol{A}_{\boldsymbol{u} u} & \mathbf{0} \\ \mathbf{0} & \boldsymbol{A}_{\varphi \varphi}\end{array}\right]\left[\begin{array}{cc}\boldsymbol{N}_{\boldsymbol{u u}} & \mathbf{0} \\ \mathbf{0} & \boldsymbol{N}_{\varphi \varphi}\end{array}\right]$ and $\boldsymbol{u}^{e}=\left[\begin{array}{c}\boldsymbol{u}_{u}^{e} \\ \boldsymbol{u}_{\varphi}^{e}\end{array}\right]$

Similarly, strain and electric field vectors can be expressed as follows:

$$
\left[\begin{array}{l}
\varepsilon \\
E
\end{array}\right]=\mathcal{B} \boldsymbol{u}^{e}
$$

with
$\mathcal{B}=\left[\begin{array}{cc}\boldsymbol{L}_{u u} & \mathbf{0} \\ \mathbf{0} & \boldsymbol{L}_{\varphi \varphi}\end{array}\right]\left[\begin{array}{cc}\boldsymbol{N}_{u u} & \mathbf{0} \\ \mathbf{0} & \boldsymbol{N}_{\varphi \varphi}\end{array}\right]$

Substituting Eqs. (4), (14) and (16) into Eq. (5), and assembling the elementary matrices yield the following classical general dynamic of motion:

$\boldsymbol{M} \ddot{\mathbf{q}}(t)+\boldsymbol{K q}(t)=\boldsymbol{F}(t)$

where $\boldsymbol{q}(t)$ contains the mechanical and electrical dofs. $\ddot{\boldsymbol{q}}(t)$ is the acceleration vector.

The matrices and vectors in the above equation are mass matrix $\boldsymbol{M}=\int_{\Omega} \rho \mathcal{N}^{T} \mathcal{N} d \Omega$, elastic matrix $\boldsymbol{K}=\int_{\Omega} \mathcal{B}^{T}\left[\begin{array}{cc}\overline{\boldsymbol{C}} & -\overline{\boldsymbol{e}}^{\boldsymbol{T}} \\ \overline{\boldsymbol{e}} & \overline{\boldsymbol{\chi}}\end{array}\right] \mathcal{B} d \Omega$, and loads vector $\boldsymbol{F}(t)=\int_{\Omega} \mathcal{N}^{T}\left[\begin{array}{l}\boldsymbol{F}_{\boldsymbol{V}} \\ -\bar{q}\end{array}\right] d \Omega+\int_{\Gamma} \mathcal{N}^{T}\left[\begin{array}{c}\boldsymbol{F}_{\boldsymbol{S}} \\ -\bar{Q}\end{array}\right] d \Gamma$.

\section{Numerical examples}

In this section, several static and dynamic tests are presented to validate the proposed finite element. The mechanical and electrical material properties which are employed in this section are given in Table 1. Present results are issued from a MATLAB program written by the authors. It is worthy to note that the exact integration procedure is employed for the calculation of the stiffness matrix of beam elements.

\subsection{Static analysis}

The accuracy and effectiveness of the present approach for static responses of FGPM beams under mechanical or electrical loading are discussed in this subsection. To this purpose, the numerical

Table 1

Mechanical and electrical properties of some piezoelectric materials.

\begin{tabular}{lcccr}
\hline & $\mathrm{PZT}-4$ & $\mathrm{BaTiO}_{3}$ & $\mathrm{Ba}_{2} \mathrm{NaNb}_{5} \mathrm{O}_{15}$ & PZT-5H \\
\hline$c_{11}^{0}(\mathrm{GPa})$ & 139 & 1660 & 239 & 127.20 \\
$c_{12}^{0}(\mathrm{GPa})$ & 77.8 & 770 & 104 & 80.21 \\
$c_{22}^{0}(\mathrm{GPa})$ & 139 & 780 & 50 & 127.20 \\
$c_{13}^{0}(\mathrm{GPa})$ & 74.3 & 1660 & 247 & 84.67 \\
$c_{23}^{0}(\mathrm{GPa})$ & 74.3 & 780 & 52 & 84.67 \\
$c_{33}^{0}(\mathrm{GPa})$ & 115 & 1620 & 135 & 117.44 \\
$c_{44}^{0}(\mathrm{GPa})$ & 25.6 & 430 & 65 & 22.99 \\
$c_{55}^{0}(\mathrm{GPa})$ & 25.6 & 430 & 66 & 22.99 \\
$c_{66}^{0}(\mathrm{GPa})$ & 30.6 & 445 & 76 & 23.47 \\
$e_{15}^{0}\left(\mathrm{~cm}^{-2}\right)$ & 12.7 & 11.6 & 2.8 & 17.03 \\
$e_{24}^{0}\left(\mathrm{~cm}^{-2}\right)$ & 12.7 & 11.6 & 3.4 & 17.03 \\
$e_{31}^{0}\left(\mathrm{~cm}^{-2}\right)$ & -5.2 & -4.4 & -0.4 & -6.62 \\
$e_{32}^{0}\left(\mathrm{~cm}^{-2}\right)$ & -5.2 & -4.4 & -0.3 & -6.62 \\
$e_{33}^{0}\left(\mathrm{~cm}^{-2}\right)$ & 15.1 & 18.6 & 4.3 & 23.24 \\
$\chi_{11}^{0}\left(10^{-8} \mathrm{Fm}^{-1}\right)$ & 1.306 & 0.112 & 0.196 & 2.771 \\
$\chi_{22}^{0}\left(10^{-8} \mathrm{Fm}^{-1}\right)$ & 1.306 & 0.112 & 0.201 & 2.771 \\
$\chi_{33}^{0}\left(10^{-8} \mathrm{Fm}^{-1}\right)$ & 1.151 & 0.126 & 0.28 & 3.010 \\
$\rho\left(\mathrm{kg} / \mathrm{m}^{3}\right)$ & 7500 & 5700 & 5300 & 7500 \\
\hline
\end{tabular}

Table 2

Mesh convergence study for the simply supported FGPM beam under the mechanical force $(a=-1)$.

\begin{tabular}{lrrrrr}
\hline \multicolumn{7}{c}{ Number of elements } \\
\cline { 2 - 6 } & \multicolumn{1}{c}{10} & \multicolumn{1}{l}{ 20 } & \multicolumn{1}{c}{30} & \multicolumn{1}{c}{40} \\
\hline$u_{3}(0.5 L, 0) \times 10^{9}$ & 1.1523 & 1.1521 & 1.1520 & 1.1520 & 1.1520 \\
$u_{1}(0,0.5 h) \times 10^{10}$ & -3.8516 & -3.8482 & -3.8467 & -3.8464 & -3.8464 \\
$\sigma_{11}(0.5 L, 0.5 h)$ & 11.4193 & 11.3507 & 11.3333 & 11.3301 & 11.3289 \\
$\sigma_{13}(0,0)$ & 2.4446 & 2.4271 & 2.4398 & 2.4537 & 2.4634 \\
$\phi(0.5 L, 0)$ & 0.0560 & 0.0556 & 0.0555 & 0.0555 & 0.0555 \\
\hline
\end{tabular}


Table 3

Convergence study for the number of the numerical layers - the simply supported FGPM beam under the mechanical force $(a=-1)$.

\begin{tabular}{|c|c|c|c|c|c|c|}
\hline & \multicolumn{6}{|c|}{ Number of layers } \\
\hline & 2 & 3 & 4 & 5 & 9 & 10 \\
\hline$u_{3}(0.5 L, 0) \times 10^{9}$ & 1.1520 & 1.1523 & 1.1520 & 1.1520 & 1.1520 & 1.1520 \\
\hline$u_{1}(0,0.5 h) \times 10^{10}$ & -3.8476 & -3.8438 & -3.8474 & -3.8467 & -3.8472 & -3.8472 \\
\hline$\sigma_{11}(0.5 L, 0.5 h)$ & 11.3261 & 11.3209 & 11.3363 & 11.3333 & 11.3363 & 11.3356 \\
\hline$\sigma_{13}(0,0)$ & 2.4307 & 2.3842 & 2.4295 & 2.4398 & 2.4295 & 2.4240 \\
\hline$\phi(0.5 L, 0)$ & 0.0556 & 0.0555 & 0.0555 & 0.0555 & 0.0555 & 0.0555 \\
\hline
\end{tabular}

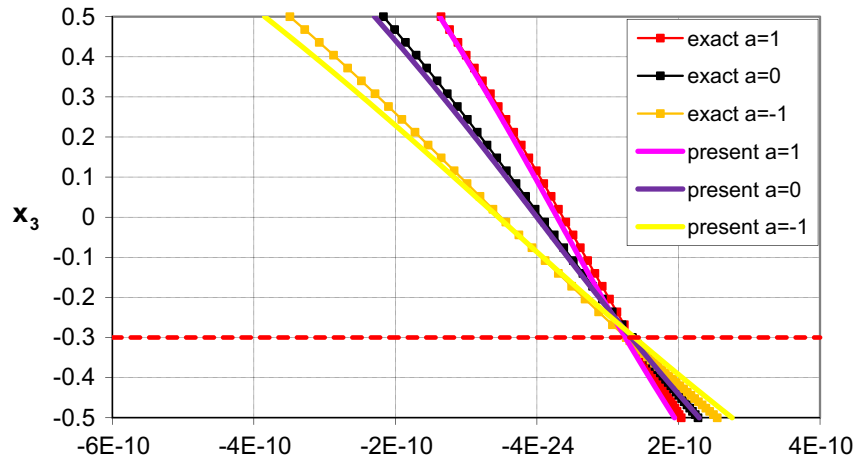

(2.1) In-plane displacement at $\left(0, x_{3}\right)$

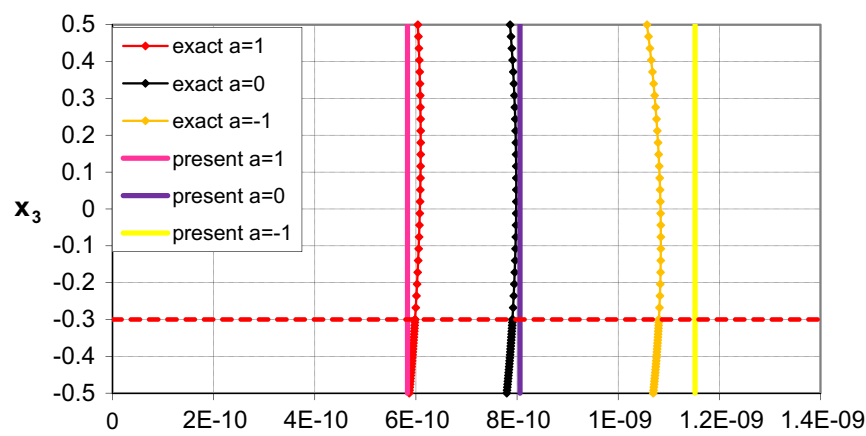

(2.2) Transverse displacement at $\left(L / 2, X_{3}\right)$

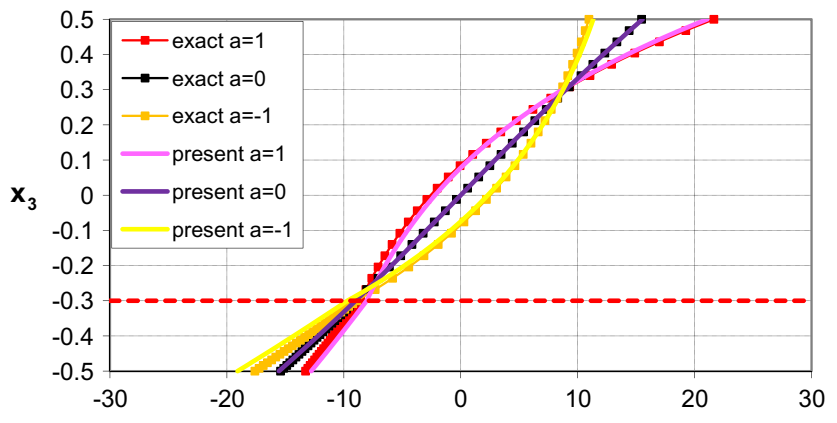

(2.3) In-plane stress 11 at $\left(L / 2, x_{3}\right)$

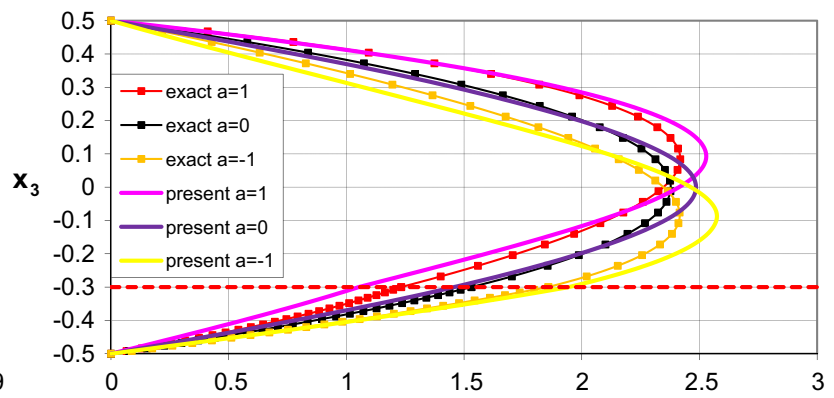

(2.4) Transverse shear stress 13 at $\left(0, x_{3}\right)$

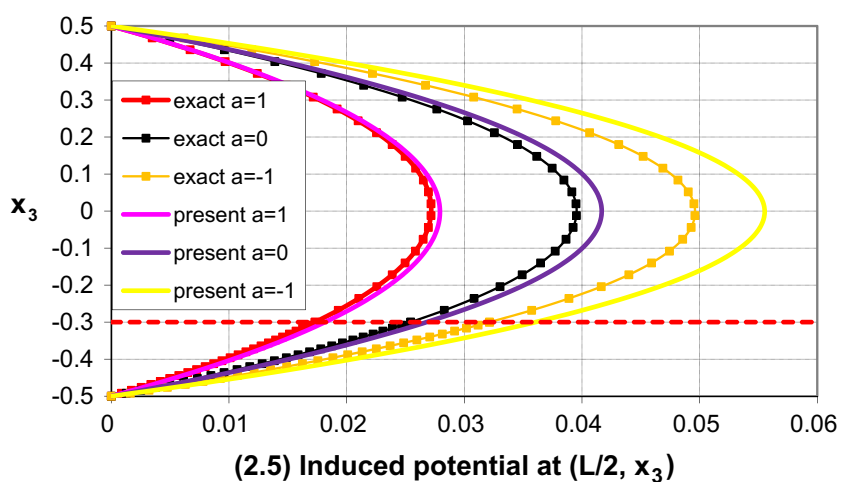

Fig. 2. Through-the-thickness distributions of $u_{1}, u_{3}, \sigma_{11}, \sigma_{13}$ and $\varphi$ in the simply supported two-layer FGPM beam under the sinusoidal mechanical force.

results obtained from the present FE are compared with reference solutions (exact piezoelectric solution [16] or commercial software ABAQUS).

\subsubsection{Simply-supported 2-layer FGM beam}

In the first example, a simply supported two-layer FGPM beam with a total thickness $h=1 \mathrm{~m}$ and length-to-thickness ratio $S=L / h=5$ is analyzed. The lower layer is made of a homogeneous PZT-4 piezoelectric material with the material properties given in Table 1 . The upper layer is a PZT-4 based exponentially graded piezoelectric layer with the following material properties:

$c_{k l}=c_{k l}^{0} f\left(x_{3}\right), \quad e_{i k}=e_{i k}^{0} f\left(x_{3}\right), \quad \chi_{i j}=\chi_{i j}^{0} f\left(x_{3}\right)$

where

$f\left(x_{3}\right)=e^{a\left(x_{3}+0.3\right)}, \quad-0.3<x_{3}<0.5$ 


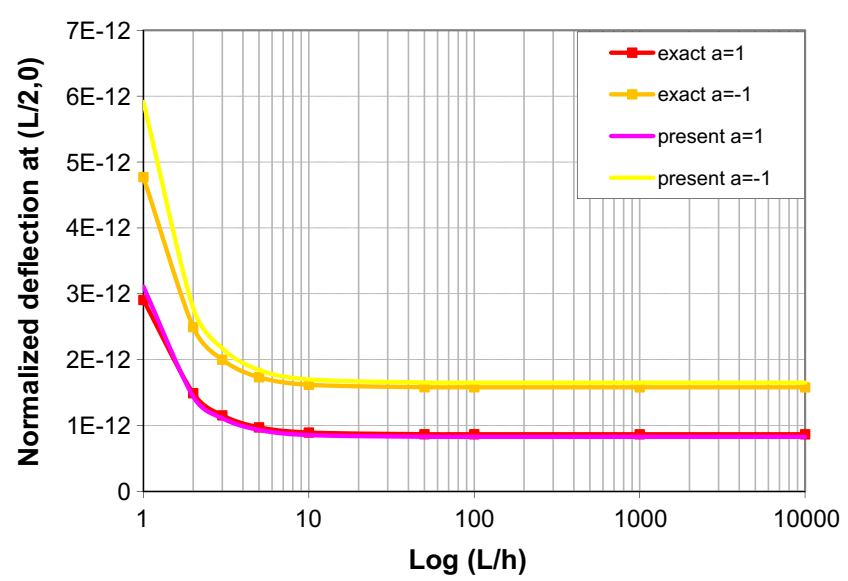

Fig. 3. Variation of the normalized transverse displacement $\bar{u}_{3}=u_{3}(L / 2,0) / S^{4}$ with respect to aspect ratio - the two-layer FGPM beam under the sinusoidal mechanical force; mesh: 20 beam elements with five layers.

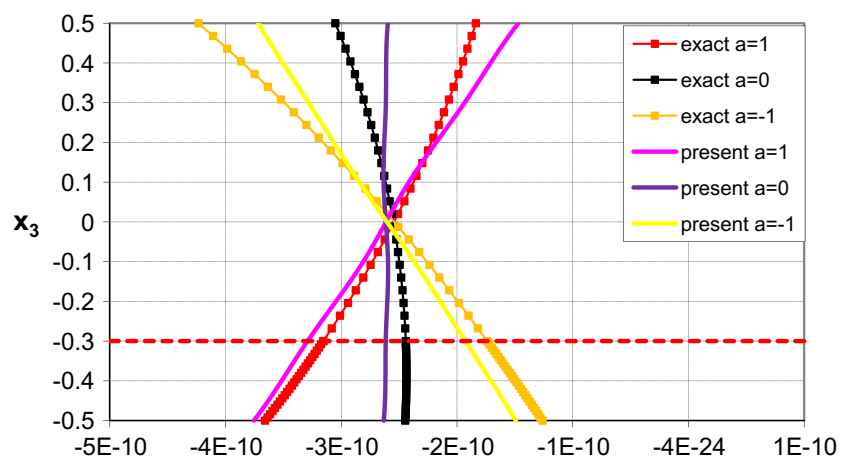

(4.1) In-plane displacement at $\left(0, x_{3}\right)$

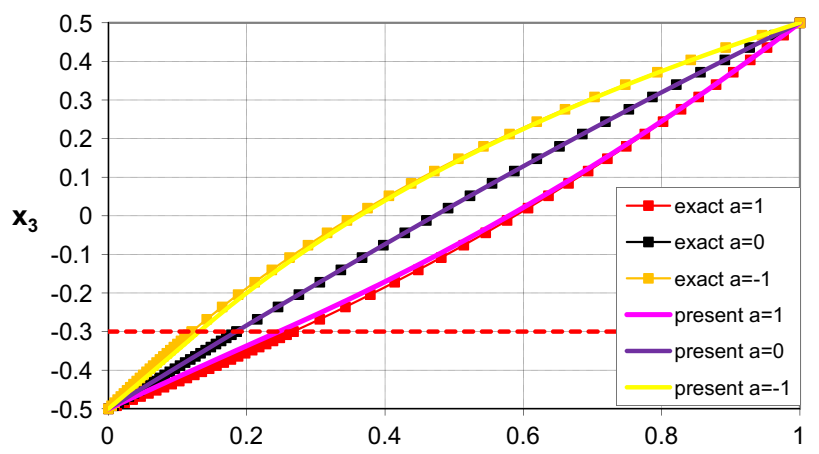

(4.2) Induced potential at $\left(L / 2, x_{3}\right)$

Fig. 4. Through-the-thickness variations of $u_{1}$ and $\varphi$ in the two-layer FGPM beam under the sinusoidal electric potential.

$a$ is a constant characterizing the gradient along $x_{3}$. The ratio between the thickness of the upper graded layer and the lower homogeneous layer is taken as 4 . The obtained numerical results are compared with exact 3D piezoelectric solution [16].

Sensor case. The two layered FGPM beam is first subjected to a sinusoidal load defined by $F_{3}\left(x_{1}, h / 2\right)=\sin \left(\pi x_{1} / L\right)$. The electric boundary condition is assumed to be closed circuit (CC). A convergence study with respect to the mesh is first carried out. Due to the symmetry, only one half of the FGPM beam is modeled. Regular mesh with 5, 10, 20, 30 and 40 elements are considered. The homogeneous piezoelectric layer is modelized by one layer while the

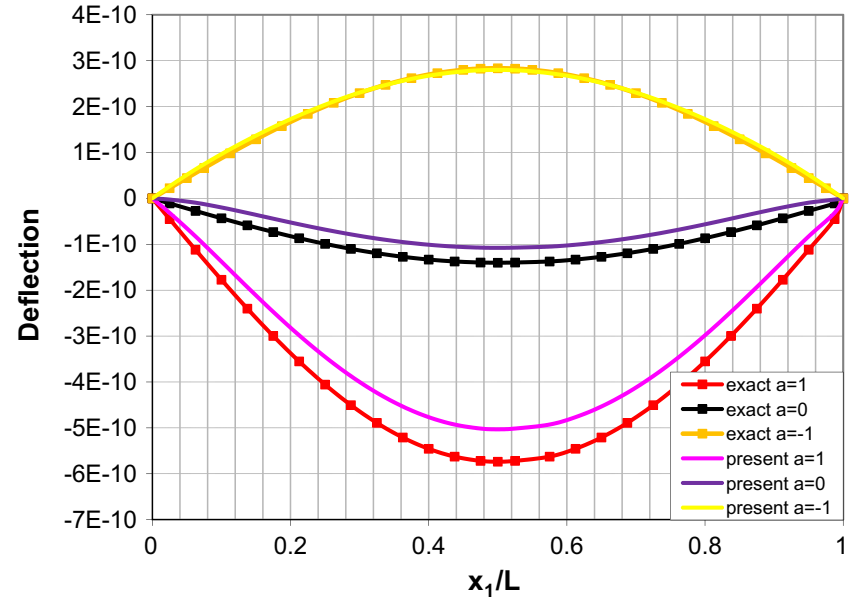

Fig. 5. Centerline deflections of the FGPM beam for various volume fraction indexes $a$ under electrical loading.

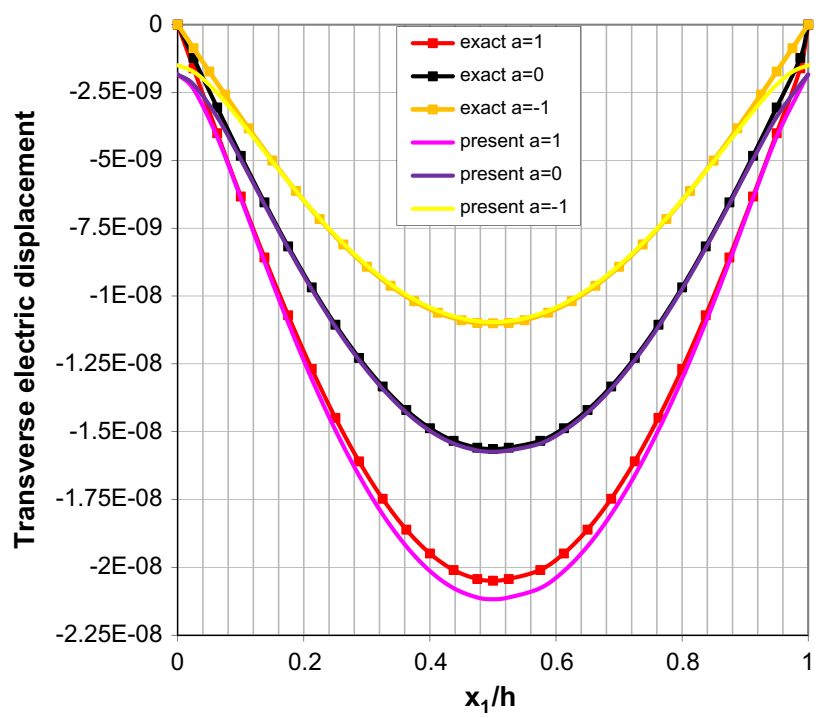

Fig. 6. Transverse electric displacement along the centerline of the FGPM beam for various volume fraction indexes $a$ under electrical loading.

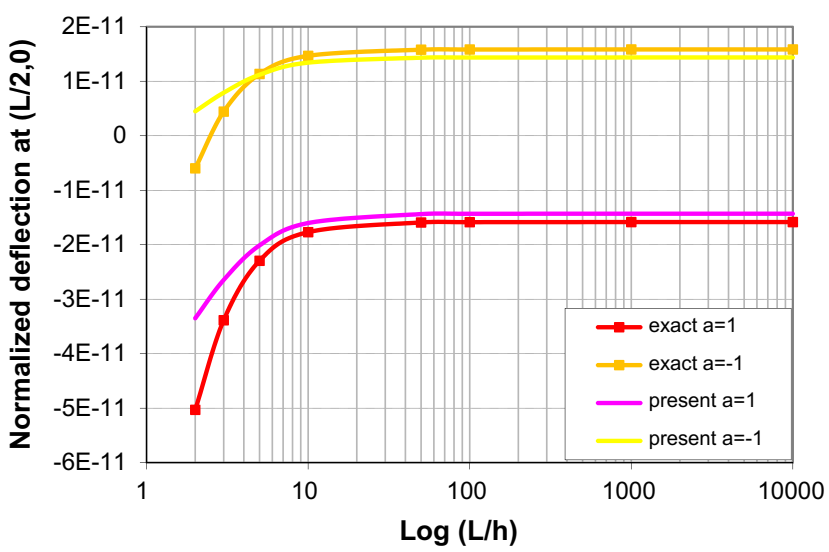

Fig. 7. Variation of the normalized transverse displacement $\tilde{u}_{3}=u_{3}(L / 2,0) / S^{2}$ with respect to aspect ratio - the two-layer FGPM beam under the sinusoidal electric potential; mesh: 20 beam elements with five layers. 


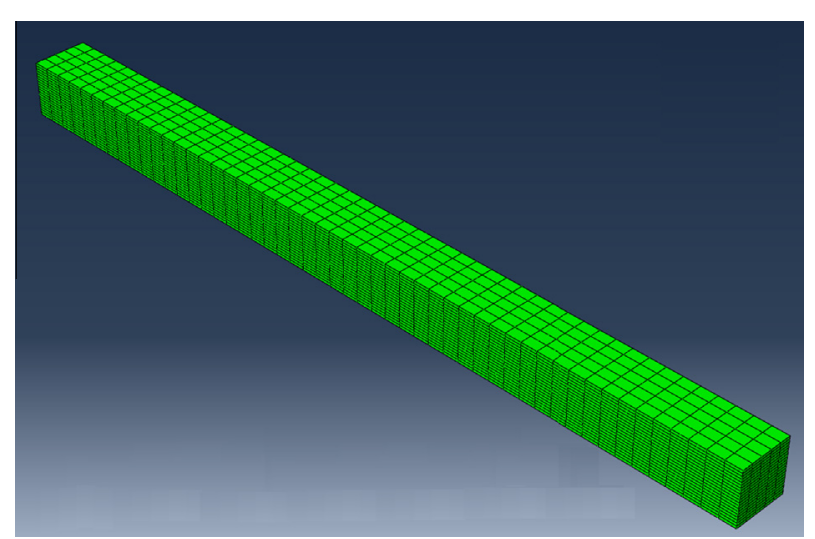

Fig. 8. FGPM beam; mesh with 5000 elements (ABAQUS).

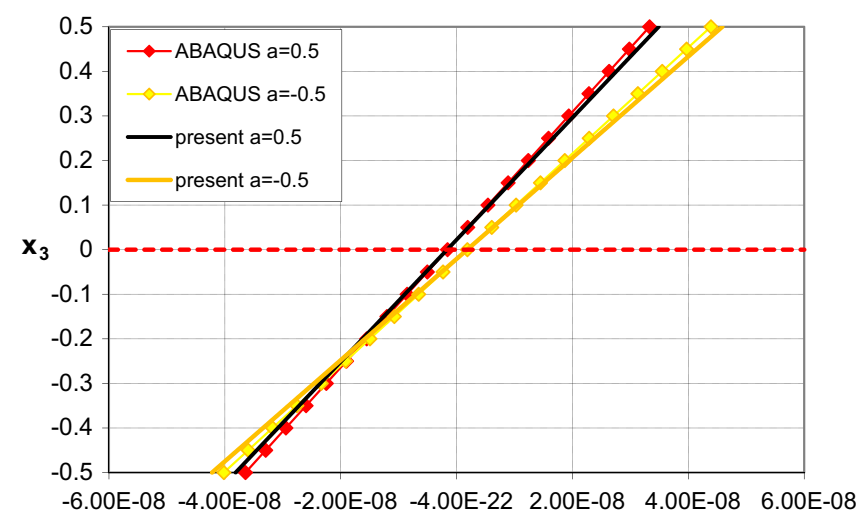

(9.1) In-plane displacement at $\left(L, X_{3}\right)$

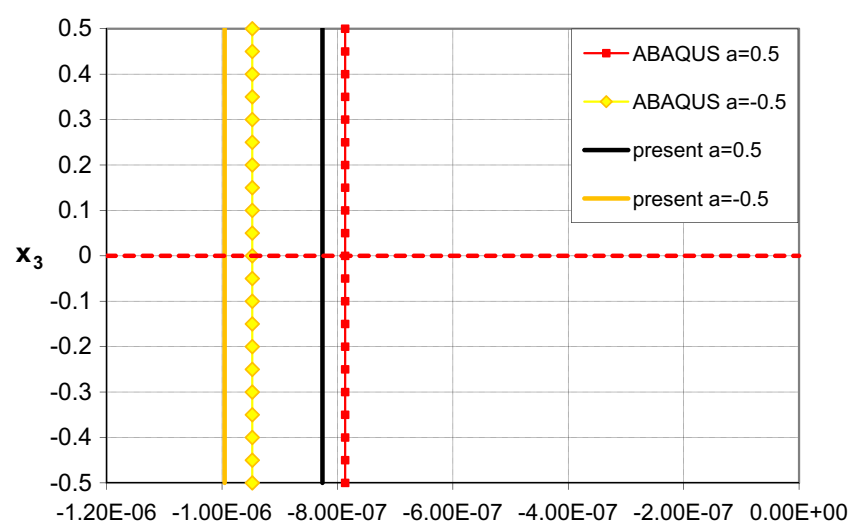

(9.2) Transverse displacement at $\left(L, X_{3}\right)$ graded piezoelectric layer uses four layers. The obtained numerical results are shown in Table 2 for the material property gradient index $a=-1$. It is seen from Table 2 that the convergence rate of the proposed finite element is very high. Then, a convergence study is also carried out for the discretization of the electric potential. To this aim, the beam is discretized into 20 elements and 2, 3, 4, 5, 9 and 10 layers. The corresponding numerical results are shown in Table 3. The obtained results with five and ten layers are very close. So, it can be inferred from Table 2 and Table 3 that 20 elements and five numerical layers for the whole thickness are sufficient to model the FGPM beam for a static analysis.

The through-thickness distributions of $u_{1}, u_{3}, \sigma_{11}, \sigma_{13}$ and $\varphi$ with CC electric boundary conditions are shown in Fig. 2. In this figure, the material property gradient index $a$ takes the three values: $-1,0,1$. For the material gradient index $a=0$, homogeneous

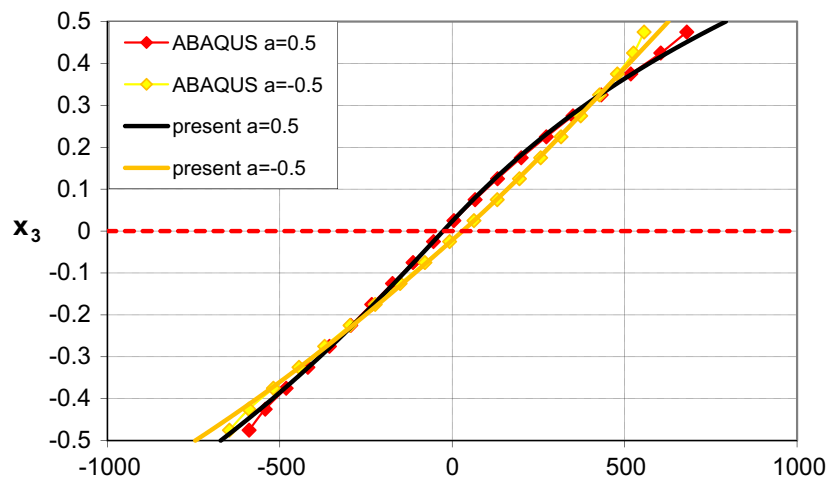

(9.3) In-plane stress 11 at $\left(0, x_{3}\right)$

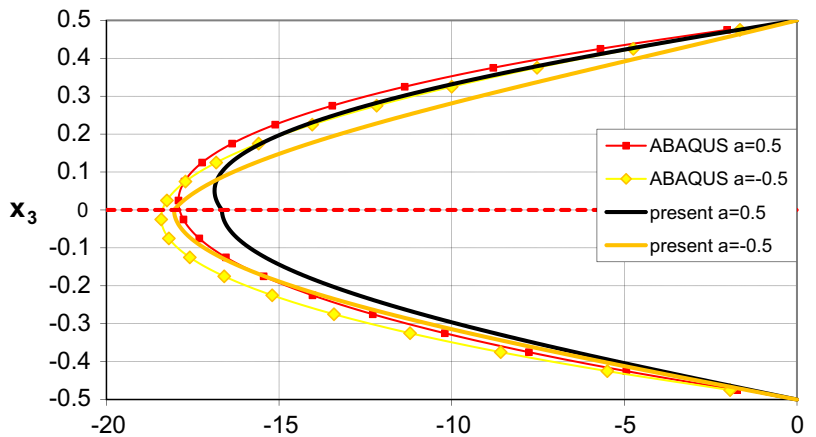

(9.4) Transverse shear stress 13 at $\left(L / 4, X_{3}\right)$

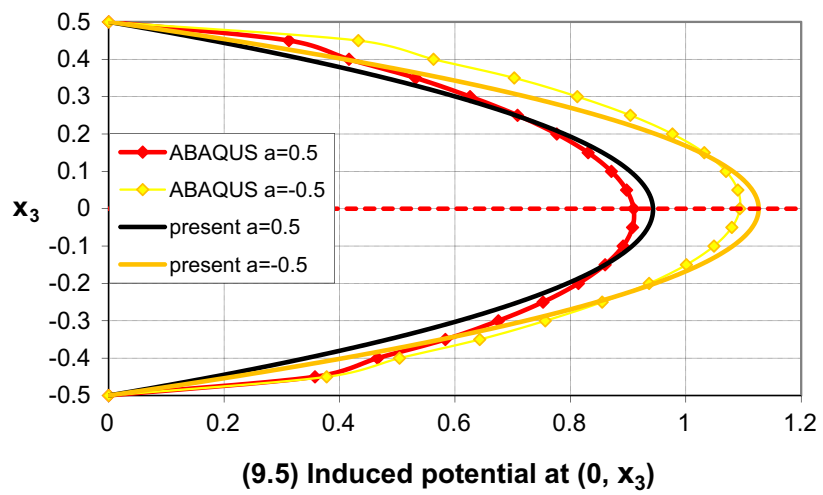

Fig. 9. Through-the-thickness distributions of $u_{1}, u_{3}, \sigma_{11}, \sigma_{13}$ and $\varphi$ in the cantilever FGPM beam under the uniform pressure. 
piezoelectric materials are recovered. The effect of continuous through-thickness variations of the material properties is obvious in these figures. It is observed from Fig. 2 that the in-plane displacement and the in-plane stress distributions obtained from the present model are in very good agreement with the exact solution. For three different material gradient indexes $-1,0,1$, the present refined sinus finite element predicts the shear stress distribution with a maximal percent error of 6.57. It is worthy to note that the transverse shear stress is obtained directly from the constitutive equations. The present model gives also good results in the prediction of induced electric potential and transverse displacement. When the material gradient index $a$ increases, the corresponding error rate of the present refined sinus finite element decreases. For soft gradient materials $(a \leqslant 0)$, the nonlinearity of $u_{3}$ across the thickness of the FGPM beam increases. Since the present refined sinus model assumes a constant distribution for the transverse displacement $u_{3}$, the corresponding error of the present
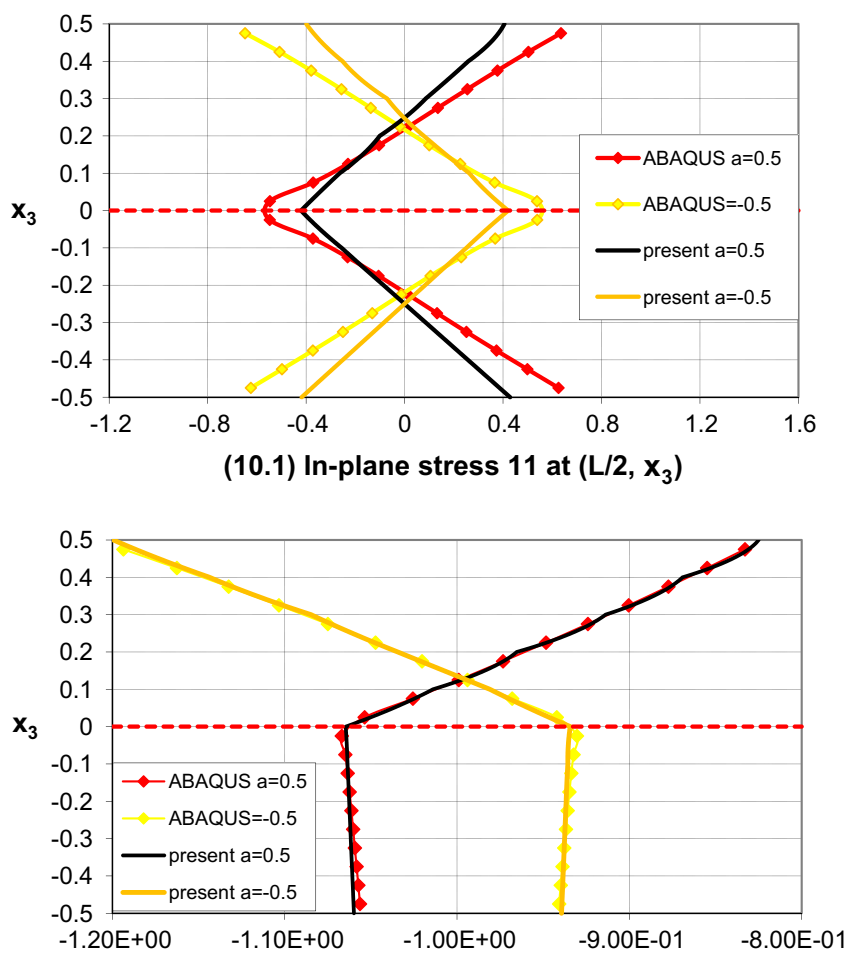

(10.2) Transverse electric displacement at $\left(L / 2, x_{3}\right)$

Fig. 10. Through-the-thickness variations of $\sigma_{11}$ and $E_{3}$ in the cantilever FGPM beam under the applied electric voltage.

model increases when decreasing the material gradient index.

Fig. 3 shows the normalized transverse displacement obtained at the middle of the simply supported FGPM beam with respect to various aspect ratios. Comparison of the present results with the exact solution demonstrates that the present approach drives to very good results regardless of the value of a. It also shows that the FE beam does not suffer from shear locking phenomenon.

Actuator case. In this case, the electric potential $\varphi\left(x_{1}, h / 2\right)=\sin \pi x_{1} / L$ is applied to the top of the functionally layered piezoelectric beam. The top and bottom surfaces of the beam are traction-free. The variation of the in-plane displacement $u_{1}$ and the electric potential $\varphi$ are shown in Fig. 4 as a function of the beam thickness coordinate $x_{3}$. In this figure, the exact piezoelasticity results are also shown and compared with the present results. It is seen that the agreement between the present results and the ex-
Table 4

Mesh convergence study for the simply supported FGPM beam - close circuit electric boundary conditions $-S=5$.

\begin{tabular}{|c|c|c|c|c|}
\hline \multicolumn{5}{|c|}{ Non-dimensional natural frequencies } \\
\hline & \multicolumn{4}{|c|}{ Number of element } \\
\hline & 5 & 10 & 20 & 40 \\
\hline Bend & 0.2477 & 0.2478 & 0.2478 & 0.2478 \\
\hline Bend & 0.8598 & 0.8608 & 0.8610 & 0.8611 \\
\hline$t / c$ & 1.4648 & 1.4647 & 1.4647 & 1.4647 \\
\hline Bend & 1.6505 & 1.6549 & 1.6566 & 1.6571 \\
\hline Bend & 2.5111 & 2.5342 & 2.5408 & 2.5426 \\
\hline$t / c$ & 2.9060 & 2.9027 & 2.9027 & 2.9027 \\
\hline Bend & 3.3157 & 3.4526 & 3.4722 & 3.4773 \\
\hline $\mathrm{sh}$ & 4.1372 & 4.1555 & 4.1586 & 4.1595 \\
\hline$t / c$ & 4.2797 & 4.2895 & 4.2881 & 4.2880 \\
\hline sh & 4.5387 & 4.5729 & 4.5828 & 4.5853 \\
\hline Bend & 4.3119 & 4.3863 & 4.4353 & 4.4475 \\
\hline
\end{tabular}

Table 5

Convergence study for the number of numerical layers - the simply supported FGPM beam - closeed circuit electric boundary conditions $-S=5$.

\begin{tabular}{llll}
\hline \multicolumn{4}{l}{ Non-dimensional natural frequencies } \\
\hline \multicolumn{4}{l}{ Number of sub-layers in piezoelectric layer } \\
\cline { 2 - 4 } & 1 & 3 & 5 \\
\hline Bend & 0.2478 & 0.2479 & 0.2478 \\
Bend & 0.8605 & 0.8616 & 0.8611 \\
$t / c$ & 1.4647 & 1.4648 & 1.4647 \\
Bend & 1.6550 & 1.6582 & 1.6571 \\
Bend & 2.5369 & 2.5433 & 2.5426 \\
$t / c$ & 2.9025 & 2.9029 & 2.9027 \\
Bend & 3.4648 & 3.4755 & 3.4773 \\
sh & 4.1519 & 4.1669 & 4.1595 \\
$t / c$ & 4.2875 & 4.2886 & 4.2880 \\
sh & 4.5773 & 4.5911 & 4.5853 \\
Bend & 4.4236 & 4.4397 & 4.4475 \\
\hline
\end{tabular}

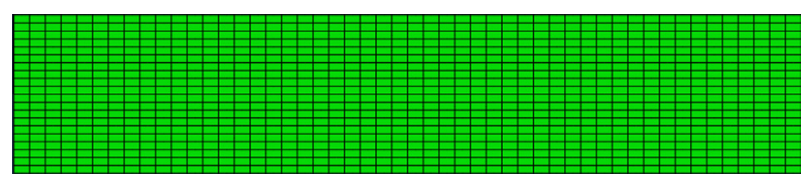

Fig. 11. FGPM beam; mesh with 1000 elements (ABAQUS).

act solutions is good. It can be also observed from this figure that in contrast to a homogeneous piezoelectric actuator, the distribution of the electric potential in the graded piezoelectric actuators is nonlinear. This effect is very well-captured using the present finite element. The centerline deflection and transverse electric displacement along the dimensionless length of the beam are shown in Figs. 5 and 6 respectively. For various volume fraction indexes $a$, the present FE predicts the deflection of the thick FGPM beam with a maximum error rate of $23.1 \%$. For the transverse electric displacement, this value is $13.6 \%$. The discrepancy between the present and exact results can be explained by the assumption on the electrical transverse normal strains which are neglected in the proposed refined sinus model. The transverse normal strains induced through the piezoelectric layers have significant effects on the electromechanical response of piezoelectric structures under electrical loadings [9]. In gradient piezoelectric materials with high electromechanical properties, the effects of these electrical transverse normal strains are more significant. Due to this reason, the error of the present model increases with increasing the material gradient index. 
Table 6

Closed circuit natural frequencies of the simply supported FGPM beam ( $a=1)$.

\begin{tabular}{|c|c|c|c|c|}
\hline \multirow[t]{2}{*}{$S$} & \multicolumn{4}{|c|}{ Non-dimensional natural frequencies } \\
\hline & & Present & ABAQUS & Error $(\%)$ \\
\hline \multirow[t]{11}{*}{5} & Bend & 0.2478 & 0.2567 & 3.47 \\
\hline & Bend & 0.8611 & 0.893 & 3.57 \\
\hline & $t / c$ & 1.4647 & 1.4637 & 0.07 \\
\hline & Bend & 1.6571 & 1.7172 & 3.50 \\
\hline & Bend & 2.5426 & 2.6254 & 3.15 \\
\hline & $t / c$ & 2.9027 & 2.862 & 1.42 \\
\hline & Bend & 3.4773 & 3.5664 & 2.50 \\
\hline & sh & 4.1595 & 4.0621 & 2.40 \\
\hline & $t / c$ & 4.2880 & 4.1095 & 4.34 \\
\hline & sh & 4.5853 & 4.4515 & 3.01 \\
\hline & Bend & 4.4475 & 4.5106 & 1.40 \\
\hline \multirow[t]{11}{*}{10} & Bend & 0.0649 & 0.0671 & 3.28 \\
\hline & Bend & 0.2475 & 0.2564 & 3.47 \\
\hline & Bend & 0.5210 & 0.5403 & 3.57 \\
\hline & $t / c$ & 0.7341 & 0.7357 & 0.22 \\
\hline & Bend & 0.8585 & 0.8909 & 3.64 \\
\hline & Bend & 1.2398 & 1.2866 & 3.64 \\
\hline & $t / c$ & 1.4645 & 1.4635 & 0.07 \\
\hline & Bend & 1.6517 & 1.7128 & 3.57 \\
\hline & Bend & 2.0853 & 2.1594 & 3.43 \\
\hline & $t / c$ & 2.1880 & 2.1752 & 0.59 \\
\hline & Bend & 2.5349 & 2.6200 & 3.25 \\
\hline \multirow[t]{11}{*}{20} & Bend & 0.0164 & 0.0170 & 3.53 \\
\hline & Bend & 0.0648 & 0.0671 & 3.43 \\
\hline & Bend & 0.1429 & 0.1480 & 3.45 \\
\hline & Bend & 0.2473 & 0.2563 & 3.51 \\
\hline & $t / c$ & 0.3673 & 0.3683 & 0.27 \\
\hline & Bend & 0.3743 & 0.3881 & 3.56 \\
\hline & Bend & 0.5203 & 0.5399 & 3.63 \\
\hline & Bend & 0.6822 & 0.7081 & 3.66 \\
\hline & $t / c$ & 0.7340 & 0.7357 & 0.23 \\
\hline & Bend & 0.8571 & 0.8899 & 3.69 \\
\hline & Bend & 1.0428 & 1.0830 & 3.71 \\
\hline
\end{tabular}

The normalized deflection of the active FGPM beam with respect to the length-to-thickness ratio is shown in Fig. 7 along with the exact piezoelasticity solutions for two values of the material property gradient index $a=-1,1$. Similar to the sensor case, it can be inferred from this figure that the present FE gives accurate results for the actuator behavior of both thick and thin FGPM beams. Again, no shear locking phenomenon occurs.

\subsubsection{Cantilever 2-layered FGPM beam}

A cantilever two-layered FGPM beam with thickness $h=1 \mathrm{~m}$, width $b=1 \mathrm{~m}$ and length to thickness ratio $S=L / h=15$ is analyzed using the present refined sinus finite element. The lower layer is made of an homogeneous PZT-4 piezoelectric material with the material properties mentioned in example 1 . The upper layer is a PZT-4 based piezoelectric FGM layer with the following material properties:

$c_{k l}=c_{k l}^{0} f\left(x_{3}\right), e_{i k}=e_{i k}^{0} f\left(x_{3}\right), \chi_{i j}=\chi_{i j}^{0} f\left(x_{3}\right)$

where

$f\left(x_{3}\right)=e^{a x_{3}}, 0<x_{3}<0.5$

In this example, the ratio of the upper graded layer to the lower homogeneous layer is equal to 1 . The material property gradient index takes the values -0.5 and 0.5 . A mesh of 40 equal sized beam elements and five numerical layers are used.

4.1.2.1. Sensor case. Fig. 9 shows the through-thickness distributions of $u_{1}, u_{3}, \sigma_{11}, \sigma_{13}$ and $\varphi$ in different sections of the beam under a uniform pressure $p\left(x_{1}, h / 2\right)=1 \mathrm{kN} / \mathrm{m}^{2}$. In this figure, the
Table 7

Closed circuit natural frequencies of the simply supported FGPM beam $(a=0)$.

\begin{tabular}{|c|c|c|c|c|}
\hline \multirow[t]{2}{*}{$S$} & \multicolumn{4}{|c|}{ Non-dimensional natural frequencies } \\
\hline & & Present & ABAQUS & Error $(\%)$ \\
\hline \multirow[t]{11}{*}{5} & Bend & 0.1940 & 0.2015 & 3.72 \\
\hline & Bend & 0.6738 & 0.6997 & 3.70 \\
\hline & $t / c$ & 1.1193 & 1.1157 & 0.32 \\
\hline & Bend & 1.2954 & 1.3418 & 3.46 \\
\hline & Bend & 1.9849 & 2.0460 & 2.99 \\
\hline & $t / c$ & 2.2386 & 2.2058 & 1.49 \\
\hline & Bend & 2.7104 & 2.7752 & 2.33 \\
\hline & sh & 3.2148 & 3.2071 & 0.24 \\
\hline & $t / c$ & 3.3579 & 3.2190 & 4.32 \\
\hline & sh & 3.5306 & 3.5057 & 0.71 \\
\hline & Bend & 3.4607 & 3.5156 & 1.56 \\
\hline \multirow[t]{11}{*}{10} & Bend & 0.0508 & 0.0527 & 3.61 \\
\hline & Bend & 0.1937 & 0.2013 & 3.78 \\
\hline & Bend & 0.4078 & 0.4239 & 3.80 \\
\hline & $t / c$ & 0.5596 & 0.5592 & 0.07 \\
\hline & Bend & 0.6717 & 0.6981 & 3.78 \\
\hline & Bend & 0.9697 & 1.0068 & 3.68 \\
\hline & $t / c$ & 1.1193 & 1.1157 & 0.32 \\
\hline & Bend & 1.2910 & 1.3384 & 3.54 \\
\hline & $t / c$ & 1.6789 & 1.6661 & 0.77 \\
\hline & Bend & 1.6290 & 1.6851 & 3.33 \\
\hline & Bend & 1.9788 & 2.0417 & 3.08 \\
\hline \multirow[t]{12}{*}{20} & Bend & 0.0129 & 0.0134 & 3.73 \\
\hline & Bend & 0.0508 & 0.0527 & 3.61 \\
\hline & Bend & 0.1119 & 0.1162 & 3.70 \\
\hline & Bend & 0.1936 & 0.2012 & 3.78 \\
\hline & $t / c$ & 0.2798 & 0.2798 & 0.00 \\
\hline & Bend & 0.2930 & 0.3046 & 3.81 \\
\hline & Bend & 0.4073 & 0.4235 & 3.83 \\
\hline & Bend & 0.5339 & 0.5551 & 3.82 \\
\hline & $t / c$ & 0.5596 & 0.5592 & 0.07 \\
\hline & Bend & 0.6706 & 0.6973 & 3.83 \\
\hline & $t / c$ & 0.8395 & 0.8380 & 0.18 \\
\hline & Bend & 0.8158 & 0.8479 & 3.79 \\
\hline
\end{tabular}

results of ABAQUS software is shown for comparison with the present results. Concerning the ABAQUS results, a coupled 3D finite element analysis is carried out using the 20 -node piezoelectric solid element (C3D20RE) available in this software. The thickness of the FGPM beam is discretized into several thin homogeneous layers with different electrical and mechanical material properties. The results computed with a mesh of 5000 elements shown in Fig. 8 can be considered as a reference. Fig. 9 shows that the distributions of the displacement components and the in-plane stress predicted from the present model are in very good agreement with the ABAQUS results. The present refined sinus FE predicts the shear stress distribution of the cantilever FGPM beam directly from constitutive equations with an error rate of less than $6 \%$. In case of induced electric potential, this value is $4 \%$.

4.1.2.2. Actuator case. An electric voltage of $V=1 V$ is applied on the FGPM cantilever beam. The through-thickness variations of inplane stress $\sigma_{11}$ and transverse electric field $E_{3}$ are shown in Fig. 10 as a function of the beam thickness coordinate. Similar to the sensor case, the results of ABAQUS software allows us to compare our approach with a reference solution. It is seen that the agreement between the present results with those obtained from ABAQUS is good. However, it is worthy to note that the converged mesh of the coupled 3D finite element model (ABAQUS) involves about 5043; degrees of freedom (dofs). In the proposed finite element formulation, only 499 dofs are used. This comparison shows that the proposed model is computationally much less costly than the coupled 3D finite element model available in the commercial software. 
Table 8

Closed circuit natural frequencies of the simply supported FGPM beam $(a=-1)$.

\begin{tabular}{|c|c|c|c|c|}
\hline \multirow[t]{2}{*}{$\mathrm{S}$} & \multicolumn{4}{|c|}{ Non-dimensional natural frequencies } \\
\hline & & Present & ABAQUS & Error $(\%)$ \\
\hline \multirow[t]{11}{*}{5} & Bend & 0.1503 & 0.1565 & 3.96 \\
\hline & Bend & 0.5223 & 0.5445 & 4.08 \\
\hline & $\mathrm{t} / \mathrm{c}$ & 0.8884 & 0.8891 & 0.08 \\
\hline & Bend & 1.0051 & 1.0471 & 4.01 \\
\hline & Bend & 1.5420 & 1.6008 & 3.67 \\
\hline & $\mathrm{t} / \mathrm{c}$ & 1.7606 & 1.7378 & 1.31 \\
\hline & Bend & 2.1087 & 2.1742 & 3.01 \\
\hline & sh & 2.5245 & 2.4646 & 2.43 \\
\hline & $\mathrm{t} / \mathrm{c}$ & 2.6010 & 2.4940 & 4.29 \\
\hline & $\mathrm{sh}$ & 2.7828 & 2.7024 & 2.98 \\
\hline & Bend & 2.6967 & 2.7483 & 1.88 \\
\hline \multirow[t]{11}{*}{10} & Bend & 0.0393 & 0.0409 & 3.91 \\
\hline & Bend & 0.1501 & 0.1564 & 4.03 \\
\hline & Bend & 0.3160 & 0.3295 & 4.10 \\
\hline & $t / c$ & 0.4452 & 0.4469 & 0.38 \\
\hline & Bend & 0.5207 & 0.5432 & 4.14 \\
\hline & Bend & 0.7520 & 0.7846 & 4.15 \\
\hline & $t / c$ & 0.8883 & 0.8890 & 0.08 \\
\hline & Bend & 1.0018 & 1.0445 & 4.09 \\
\hline & Bend & 1.2647 & 1.3168 & 3.96 \\
\hline & $t / c$ & 1.3271 & 1.3213 & 0.44 \\
\hline & Bend & 1.5374 & 1.5978 & 3.78 \\
\hline \multirow[t]{11}{*}{20} & Bend & 0.0100 & 0.0104 & 3.85 \\
\hline & Bend & 0.0393 & 0.0409 & 3.91 \\
\hline & Bend & 0.0867 & 0.0903 & 3.99 \\
\hline & Bend & 0.1500 & 0.1563 & 4.03 \\
\hline & $t / c$ & 0.2228 & 0.2238 & 0.45 \\
\hline & Bend & 0.2270 & 0.2367 & 4.10 \\
\hline & Bend & 0.3156 & 0.3292 & 4.13 \\
\hline & Bend & 0.4138 & 0.4318 & 4.17 \\
\hline & $t / c$ & 0.4452 & 0.4469 & 0.38 \\
\hline & Bend & 0.5199 & 0.5426 & 4.18 \\
\hline & Bend & 0.6325 & 0.6603 & 4.21 \\
\hline
\end{tabular}

\subsection{Free vibration analysis}

FGPM beams are now used to assess the proposed FE for free vibration analyses. It concerns large variety of mechanical and electrical boundary conditions with different length-to-thickness ratios. The results are compared with other available solutions reported in the literature, or 2D coupled finite element solution. The 2D coupled finite element analysis is performed using 8-node piezoelectric plane stress element in ABAQUS with a very refined mesh.

\subsubsection{PZT-4 based exponentially graded piezoelectric beam}

In this example, free vibration of a FGPM beam with the thickness $h=0.001 \mathrm{~m}$ and length-to-thickness ratio $S(L / h)=5$ (thick beam), $S=10$ (moderately thick beam) and $S=20$ (moderately thin beam) is considered. The beam is made of a PZT-4 based exponentially graded piezoelectric material with the following material properties:

$c_{k l}=c_{k l}^{0} f\left(x_{3}\right), \quad e_{i k}=e_{i k}^{0} f\left(x_{3}\right), \quad \chi_{i j}=\chi_{i j}^{0} f\left(x_{3}\right)$

where

$f\left(x_{3}\right)=e^{a x_{3} / h}$

4.2.1.1. Convergence study. A convergence study with respect to the mesh is first carried out. It is detailed below:

- Mechanical boundary conditions: simply supported beam.

- Electrical boundary conditions: CC electric boundary conditions applied on the surfaces of the beam.

- length-to-thickness ratio: $S=5$.

- Material gradient index: $a=1$.
Table 9

Open circuit natural frequencies of the simply supported FGPM beam $(S=10)$.

\begin{tabular}{|c|c|c|c|c|}
\hline \multirow[t]{2}{*}{ Material gradient index } & \multicolumn{4}{|c|}{ Non-dimensional natural frequencies } \\
\hline & & Present & ABAQUS & Error (\%) \\
\hline \multirow[t]{11}{*}{$a=1$} & Bend & 0.0650 & 0.0675 & 3.70 \\
\hline & Bend & 0.2487 & 0.2583 & 3.72 \\
\hline & Bend & 0.5254 & 0.5464 & 3.84 \\
\hline & $t / c$ & 0.7454 & 0.7721 & 3.46 \\
\hline & Bend & 0.8688 & 0.9016 & 3.64 \\
\hline & Bend & 1.2581 & 1.3041 & 3.53 \\
\hline & $t / c$ & 1.4825 & 1.5261 & 2.86 \\
\hline & Bend & 1.6786 & 1.7375 & 3.39 \\
\hline & Bend & 2.1203 & 2.1909 & 3.22 \\
\hline & $t / c$ & 2.2065 & 2.2496 & 1.92 \\
\hline & Bend & 2.5766 & 2.6571 & 3.03 \\
\hline \multirow[t]{11}{*}{$a=0$} & Bend & 0.0508 & 0.0527 & 3.61 \\
\hline & Bend & 0.1940 & 0.2015 & 3.72 \\
\hline & Bend & 0.4090 & 0.4248 & 3.72 \\
\hline & $t / c$ & 0.5695 & 0.5904 & 3.54 \\
\hline & Bend & 0.6752 & 0.7007 & 3.64 \\
\hline & Bend & 0.9765 & 1.0122 & 3.53 \\
\hline & $t / c$ & 1.1374 & 1.1743 & 3.14 \\
\hline & Bend & 1.3020 & 1.3472 & 3.36 \\
\hline & Bend & 1.6440 & 1.6976 & 3.16 \\
\hline & $t / c$ & 1.7033 & 1.7468 & 2.49 \\
\hline & Bend & 1.9973 & 2.0582 & 2.96 \\
\hline \multirow[t]{11}{*}{$a=-1$} & Bend & 0.0394 & 0.0411 & 4.14 \\
\hline & Bend & 0.1502 & 0.1567 & 4.15 \\
\hline & Bend & 0.3163 & 0.3299 & 4.12 \\
\hline & $t / c$ & 0.4527 & 0.4707 & 3.82 \\
\hline & Bend & 0.5213 & 0.5437 & 4.12 \\
\hline & Bend & 0.7535 & 0.7855 & 4.07 \\
\hline & $t / c$ & 0.9035 & 0.9369 & 3.56 \\
\hline & Bend & 1.0044 & 1.0463 & 4.00 \\
\hline & Bend & 1.2687 & 1.3203 & 3.91 \\
\hline & $t / c$ & 1.3505 & 1.3943 & 3.14 \\
\hline & Bend & 1.5426 & 1.6030 & 3.77 \\
\hline
\end{tabular}

The beam is discretized using 5, 10, 20 and 40 equal sized elements and five layers. Non-dimensional natural frequencies, $\bar{\omega}=\omega h \sqrt{\left(\rho / c_{55}\right)_{P Z T-4}}$, are shown in Table 4 . In this table, the mode shapes are precised as: bend, sh, $t / c$, for bending, shear and axial traction/compression mode respectively. It is seen from Table 4 that the convergence rate of the proposed finite element is very high. Then, a convergence study is also carried out for the discretization of the electric potential. To this aim, the beam is discretized into 40 equal sized beam elements and 1, 3 and 5 numerical layers. The corresponding numerical results are shown in Table 5. The obtained results with one and five layers are very close. So, it can be inferred from Table 4 and Table 5 that a discretization into 40 equal sized beam elements with five layers is sufficient to model a FGPM beam for free vibration analysis.

The same study is performed using ABAQUS. The thickness of the FGPM beam is discretized into several thin homogeneous layers with different electrical and mechanical material properties. The mesh with 1000 elements (9423 dofs) shown in Fig. 11 yields converged results. They will be considered as a reference. It is not detailed here for brevity reason. For solving the eigenvalue problem, the Lanczos method available in the software is employed.

4.2.1.2. Closed circuit case. The non-dimensional natural frequencies of simply-supported thick to moderately thin FGPM beams with CC electric boundary conditions are shown in Tables 6-8 for three different material gradient indexes $1,0,-1$. Homogeneous piezoelectric material is recovered for $a=0$. It gives a better insight about the effect of continuous through-the-thickness variations of material properties on the natural frequencies of piezoelectric beams. In these tables, the results of ABAQUS software have been also shown and compared with the present results. It is observed 

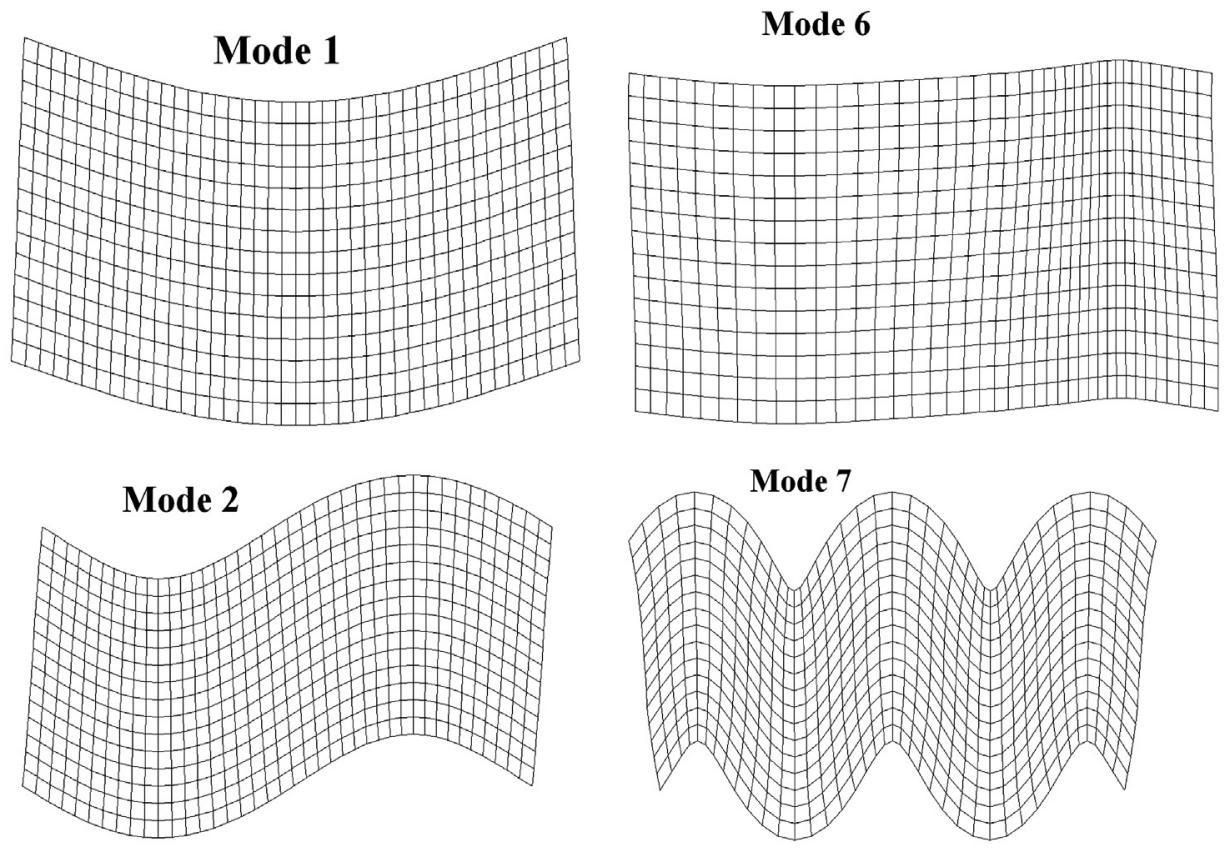

Mode 3
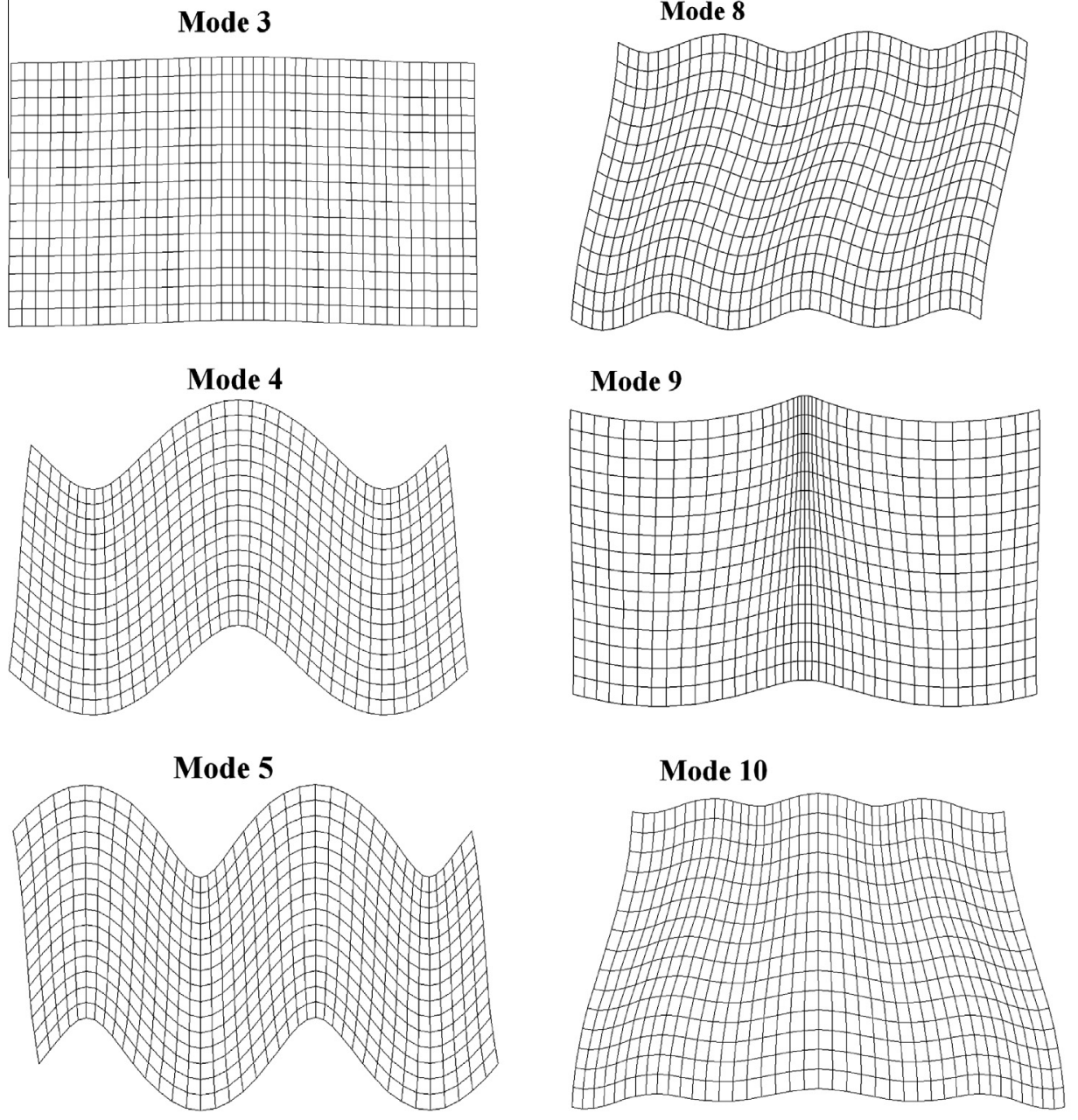

Fig. 12. First ten mode shapes of the simply supported FGPM beam with $a=1$; refined sinus model $(S=5)$.

that the natural frequencies predicted from the present approach are in very good agreement with the ABAQUS results. For three different material gradient indexes $-1,0,1$, the present refined sinus model predicts the first eleven natural frequencies of thick $(S=5)$ to moderately thin $(S=20)$ beams with a maximal percent error of 4.34. Furthermore, the converged mesh of the coupled 2D (ABAQUS) has about 1983 dofs while the proposed finite element formulation needs only 139 dofs. This comparison shows that the 
proposed model is computationally much less costly than the coupled 2D finite element model available in the commercial software.

In the prediction of bending modes, the error rate of the present refined sinus finite element increases with decreasing the material gradient index $a$. For soft gradient materials $(a \leqslant 0)$, the nonlinearity of $u_{3}$ through the thickness of the FGPM beam increases. Since the present refined sinus model assumes a constant distribution for the transverse displacement $u_{3}$, the error of the present model in the prediction of bending modes increases when decreasing the material gradient index. Nevertheless, the nonlinearity of transverse displacement has not significant effect on the shear and axial modes. For illustration, the first ten mode shapes of the thick FGPM beam are given in Fig. 12 .

4.2.1.3. Open circuit case. The open circuit case is considered. Natural frequencies of a moderately thick $(S=10)$ simply supported FGPM beam is summarized in Table 9 for three values of material gradient indexes $a=1, a=0$ and $a=-1$. Similar to the closed circuit case, the results obtained from the present finite element are very close to the ABAQUS values. The error rate in the prediction of the first eleven natural frequencies of the moderately thick beams is less than $4.15 \%$.

Compared with the results obtained in Section 4.2.1.2, we can observe that the open circuit electrical boundary conditions lead to slightly higher natural frequencies, regardless of material gradient indexes. This effect which is related to the piezoelectric coupling is very well-captured by the present model.

\subsubsection{Comparison with results available in literature}

A unimorph piezoelectric beam studied by Yang and Zhifei [21], Annigeri et al. [38] and Marcus [39] is considered in this example. This beam is composed of $\mathrm{BaTiO}_{3}$ with the material properties given in Table 1. The height and length of the beam is $h=0.02 \mathrm{~m}$ and $L=0.3 \mathrm{~m}$, respectively. C-F, S-S, C-C stands for Clamped-Free, Simply-Supported and Clamped-Clamped respectively. Yang and Zhifei [21] analyzed this beam using the SSDQM while Annigeri et al. [38] analyzed it by employing FE plate based on the 2D elas- ticity. Marcus's results [39] are based on Euler-Bernoulli beam theory.

The present results are obtained using 40 equal sized beam elements with five subdivisions of piezoelectric layer. For different kinds of boundary conditions, the non-dimensional frequencies, $\bar{\omega}=\omega h \sqrt{\left(\rho / c_{55}\right)_{\mathrm{BaTi}_{3}}}$ are summarized in Table 10 . This one shows that the results obtained from the present refined FE agree very well with the results obtained by the previous researchers.

In order to have a comparison with other investigations, free vibration of a FGPM beam with the following distribution of material properties along the thickness direction is considered:

$\psi=\left(1-f\left(x_{3}\right)\right) \psi^{B}+f\left(x_{3}\right) \psi^{T}$

where $f\left(x_{3}\right)=\left(\frac{2 x_{3}+h}{2 h}\right)^{a}$ and $\psi$ is an arbitrary material properties of the FGPM beam. $\psi^{B}$ and $\psi^{T}$ represent the values of $\psi$ on the top and bottom of the graded beam respectively. The symbol $a$ is the material gradient index. In the considered beam, the material properties vary from $100 \%$ PZT -4 at the top surface to $100 \% \mathrm{Ba}_{2} \mathrm{NaNb}_{5} \mathrm{O}_{15}$ at the bottom surface. The elastic, piezoelectric and dielectric constants for these two piezoelectric materials can be found in Table 1 . The geometric size is the same as the aforementioned unimorph beam ( $h=0.02 \mathrm{~m}$ and $L=0.3 \mathrm{~m}$ ). Similar to the unimorph case, the FGPM beam is discretized into 40 equal sized beam elements and five sub-layers. The Closed-Circuit case is considered. The first five non-dimensional fundamental frequencies $\left(\bar{\omega}=\omega h \sqrt{\left(\rho / c_{55}\right)_{\text {PZT - }}}\right)$ of the beam with $a=1$ are given in Table 11. In this table, the present refined sinus results is compared with the results of Yang and Zhifei [21]. As it can be observed in Table 11, the present results are very close to Yang and Zhifei's results.

In this example, the effect of the aspect ratio $L / h$ on the nondimensional fundamental frequency is also addressed for different boundary conditions. The present results are compared with the Yang and Zhifei's results in Fig.13. A sharp decrease in the nondimensional fundamental frequency occurs for the thick structures. This effect is particularly pronounced for the $\mathrm{C}-\mathrm{C}$ case. For $L / h>40$, the sensitivity to the aspect ratio decreases regardless of the boundary conditions.

Table 10

Non-dimensional frequencies of the homogenous piezoelectric beam composed of $\mathrm{BaTiO}_{3}$ for three different boundary conditions.

\begin{tabular}{|c|c|c|c|c|c|c|}
\hline \multirow[t]{2}{*}{ Boundary conditions } & \multirow[t]{2}{*}{ Theory } & \multicolumn{5}{|l|}{ Mode } \\
\hline & & 1 & 2 & 3 & 4 & 5 \\
\hline \multirow[t]{4}{*}{$\mathrm{C}-\mathrm{F}$} & present & 0.0075 & 0.0459 & 0.1247 & 0.1722 & 0.2348 \\
\hline & Yang and Zhifei [21] & 0.0075 & 0.0463 & 0.1259 & 0.1723 & 0.2369 \\
\hline & Annigeri et al. [38] & 0.0076 & 0.0471 & 0.1285 & 0.1757 & 0.2433 \\
\hline & Marcus [39] & 0.0074 & 0.0464 & 0.1299 & - & 0.2545 \\
\hline \multirow[t]{3}{*}{ S-S } & present & 0.0209 & 0.0819 & - & 0.1783 & 0.3042 \\
\hline & Yang and Zhifei [21] & 0.0211 & 0.0828 & - & 0.1805 & 0.3082 \\
\hline & Annigeri et al. [38] & 0.0214 & 0.0840 & 0.1635 & 0.1837 & 0.3149 \\
\hline \multirow[t]{3}{*}{$\mathrm{C}-\mathrm{C}$} & present & 0.0464 & 0.1234 & 0.2319 & 0.3445 & 0.3655 \\
\hline & Yang and Zhifei [21] & 0.0478 & 0.1272 & 0.2389 & 0.3451 & 0.3763 \\
\hline & Annigeri et al. [38] & 0.0477 & 0.1273 & 0.2410 & 0.3518 & 0.3813 \\
\hline
\end{tabular}

Table 11

The first five non-dimensional frequencies of the FGPM beam composed of PZT- 4 and $\mathrm{Ba}_{2} \mathrm{NaNb}_{5} \mathrm{O}_{15}$. Closed-Circuit case.

\begin{tabular}{|c|c|c|c|c|c|c|}
\hline \multirow[t]{2}{*}{ Boundary conditions } & \multirow[t]{2}{*}{ Theory } & \multicolumn{5}{|l|}{ Mode } \\
\hline & & 1 & 2 & 3 & 4 & 5 \\
\hline \multirow[t]{2}{*}{$\mathrm{C}-\mathrm{F}$} & present & 0.0110 & 0.0677 & 0.1839 & 0.2611 & 0.5458 \\
\hline & Yang and Zhifei [21] & 0.0112 & 0.0689 & 0.1863 & 0.2621 & 0.5476 \\
\hline \multirow[t]{2}{*}{ S-S } & present & 0.0309 & 0.1209 & 0.2629 & 0.4483 & 0.5219 \\
\hline & Yang and Zhifei [21] & 0.0314 & 0.1227 & 0.2660 & 0.4515 & 0.5229 \\
\hline \multirow[t]{2}{*}{$\mathrm{C}-\mathrm{C}$} & present & 0.0684 & 0.1821 & 0.3419 & 0.5216 & 0.5388 \\
\hline & Yang and Zhifei [21] & 0.0695 & 0.1839 & 0.3434 & 0.5247 & 0.5373 \\
\hline
\end{tabular}




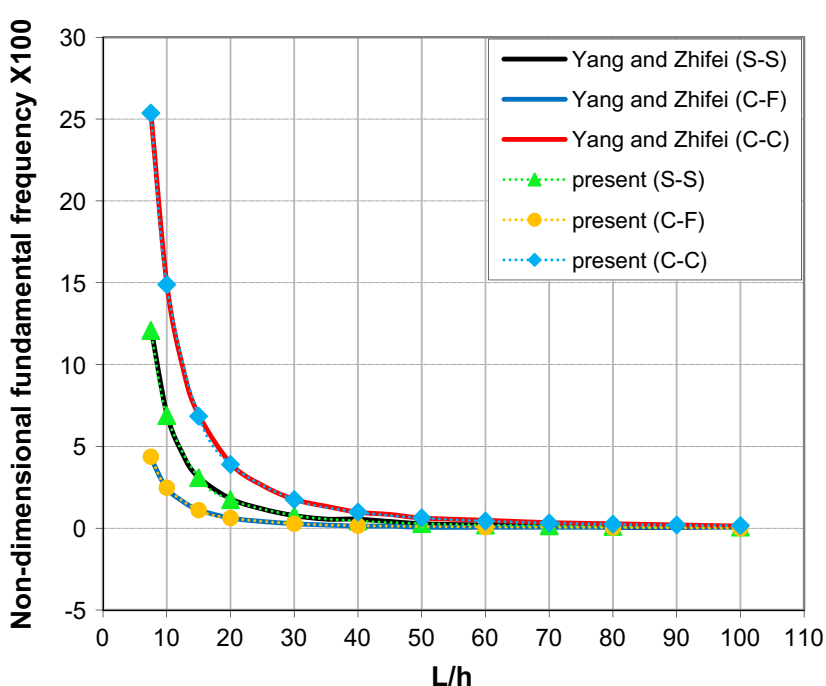

Fig. 13. Effect of $L / h$ on the fundamental frequency.

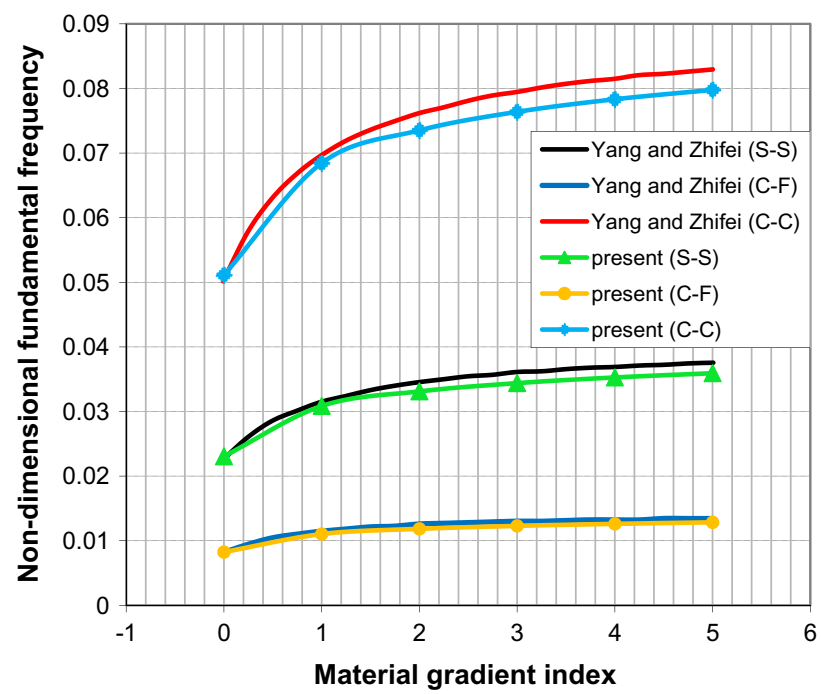

Fig. 14. Effect of the material gradient index on the fundamental frequency $-S=30$

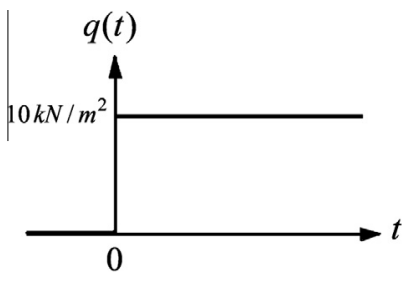

Fig. 15. Step time pressure.

The variation of the non-dimensional fundamental frequency with respect to the material gradient index is depicted in Fig. 14 for the closed-circuit case and length-to-thickness ratio $S=30$. It is seen that the fundamental frequency increases slowly with the increase of the gradient index $a$. Nevertheless, we can observe that the influence of this material parameter increases for the $\mathrm{C}-\mathrm{C}$ case. This phenomenon is very well-captured by the present FE.

As shown in Figs. 13 and 14, the present refined sinus results are also in good agreement with Yang and Zhifei's results.

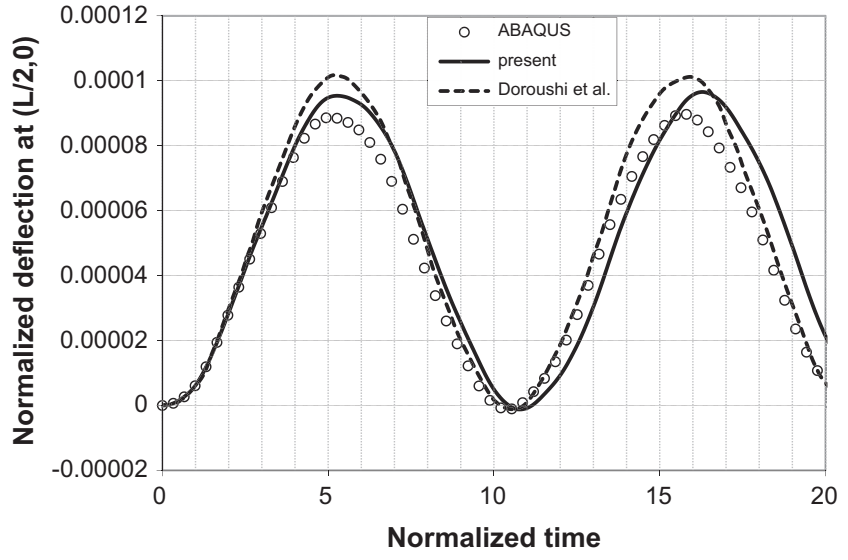

Fig. 16. Transient response of a clamped-clamped FGPM beam subjected to a suddenly applied pressure; central deflection.

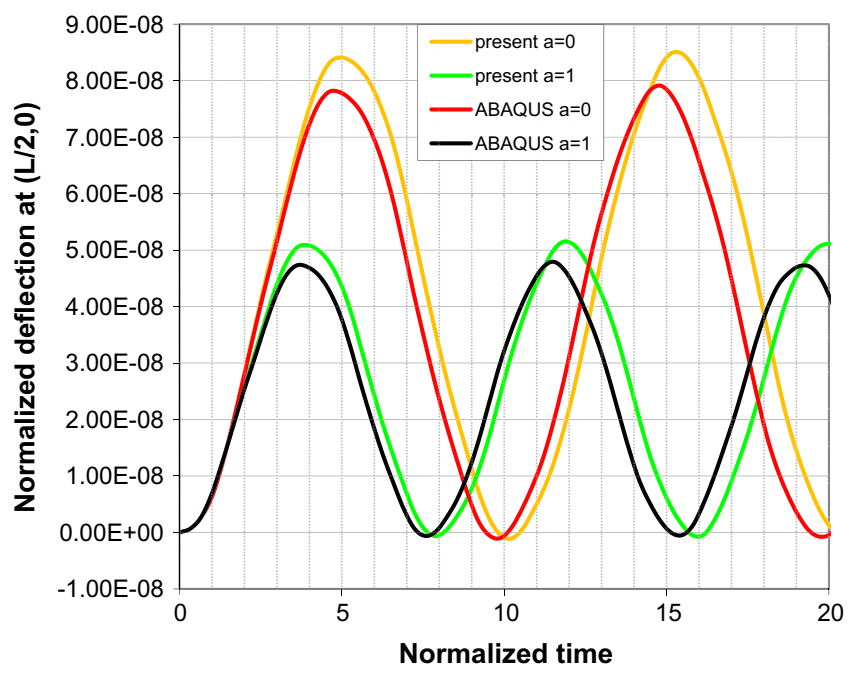

Fig. 17. Central deflection of a clamped-clamped FGPM beam subjected to the suddenly applied pressure $q=10,000 \mathrm{~N} / \mathrm{m}^{2}$.

\subsubsection{Transient analysis}

A clamped-clamped FGPM beam with the thickness $h=0.001 \mathrm{~m}$ and length-to-thickness ratio $S=10$ is analyzed using the present refined sinus model. The uniform step pressure $q(t)=10,000 S(t)$ with step time function $S(t)=1$ is applied on the top surface of this beam. This uniform step pressure is shown in Fig. 15. The material properties of this beam vary from $100 \%$ PZT-4 at the top surface to $100 \%$ PZT-5H at the bottom surface according to the following power low distribution:

$\psi=\left(1-\left(\frac{2 x_{3}+h}{2 h}\right)^{a}\right) \psi^{P Z T-5 H}+\left(\frac{2 x_{3}+h}{2 h}\right)^{a} \psi^{P Z T-4}$

The dimensionless values of deflection and time are given as $\bar{u}_{3}=u_{3} / h$ and $\bar{t}=t \sqrt{\left(81.3 \times 10^{9} / \rho\right)_{\text {PZT }-4} / L^{2}}$ respectively. The time history response of the dimensionless central deflection of the FGPM beam is shown in Fig. 16 for the material gradient index $a=1$. The results are obtained with 20 equal-size beam elements. Based on the accuracy criteria for time integration, the time step is taken as $0.0005 \mathrm{~s}$. This example has been also analyzed by Doroushi et al. [28] using the third-order shear deformation theory. In Fig. 16, the results of this theory and the results of present refined sinus model are compared with the results of ABAQUS software. The present finite element predicts the central deflection of the 
clamped-clamped FGPM beam with the maximal percent error of 6.76. This value for the third-order shear deformation theory is about 14.37 .

As a final example, transient dynamic analysis of a piezoelectric beam with the same geometry, boundary and loading conditions as previously is considered. The structure is made of a PZT-4 based exponentially graded piezoelectric material with the following material properties:

$c_{k l}=c_{k l}^{0} e^{a x_{3} / h}, \quad e_{i k}=e_{i k}^{0} e^{a x_{3} / h}, \quad \chi_{i j}=\chi_{i j}^{0} e^{a x_{3} / h}$

The dimensionless central deflection of the FGPM beam with respect to dimensionless time is shown in Fig. 17 for two values of the material gradient index $a=0$ and $a=1$. In this figure, the results of ABAQUS software are also shown for comparison. It is seen that the agreement between the two approaches is good.

All these different examples prove the efficiency of the present model for free vibration and transient analysis of FGPM beams. Compared to LWT, coupled 2D and 3D elements available in the commercial softwares, only few degrees of freedom are needed to obtain good results by the present refined sinus finite element.

\section{Conclusions}

A conforming three-nodded beam element is presented for the static, modal and transient response of FGPM beams. The kinematics is based on a refined sinus model. All displacement and transverse shear stress continuities are ensured at layer interfaces as well as the free boundary conditions on the top and bottom of the beam. The number of the mechanical unknowns remains low and is independent of the number of layers. A LayerWise high-order approximation is used for the electrical potential.

In order to assess the accuracy of the proposed finite element for static and dynamic analyses of FGPM beams, comparisons have been made with the results obtained from the coupled 2D or 3D finite element (ABAQUS) analysis and other previous published results. To this purpose, various static and dynamic tests with different geometric parameters, mechanical and electrical boundary conditions are considered. We have proved that this beam element is free from shear locking. Accurate results have been found for static bending, natural frequencies and transient responses. Moreover, the proposed model has only one generalized mechanical unknown more than FSDT. Compared to LWT, coupled 2D and 3D elements available in the commercial softwares, only few degrees of freedom are needed to obtain good results with the present refined sinus finite element. This approach seems to be a good compromise between computational cost and accuracy for piezoelectric coupling problem.

\section{References}

[1] Tzou HS, Gadre M. Theoretical analysis of a multi-layered thin shell coupled with piezoelectric shell actuators for distributed vibration controls. J Sound Vib 1989;132:433-50.

[2] Tzou HS, Tseng CI. Distributed piezoelectric sensor/actuator design for dynamic measurement/control of distributed parameter systems: a piezoelectric finite element approach. J Sound Vib 1990;138(1):17-34.

[3] Pablo F, Bruant I, Polit O. Use of classical plate finite elements for the analysis of electroactive composite plates. Numerical validations. J Intell Mater Syst Struct 2009;20(15):1861-73.

[4] D'Ottavio M, Polit O. Sensitivity analysis of thickness assumptions for piezoelectric plate models. J Intell Mater Syst Struct 2009;20(15):1815-34.

[5] Vidal P, D'Ottavio M, Thaier MB, Polit O. An efficient finite shell element for the static response of piezoelectric laminates. J Intell Mater Syst Struct 2011;22(7):671-90.

[6] Beheshti-Aval SB, Lezgy-Nazargah M. A finite element model for composite beams with piezoelectric layers using a sinus model. J Mech 2010;26(2):249-58.
[7] Beheshti-Aval SB, Lezgy-Nazargah M. Assessment of velocity-acceleration feedback in optimal control of smart piezoelectric beams. Smart Struct Syst 2010;6(8):921-38.

[8] Beheshti-Aval SB, Lezgy-Nazargah M, Vidal P, Polit O. A refined sinus finite element model for the analysis of piezoelectric laminated beams. J Intell Mater Syst Struct 2011;22:203-19.

[9] Beheshti-Aval SB, Lezgy-Nazargah M. A coupled refined high-order global-local theory and finite element model for static electromechanical response of smart multilayered/sandwich beams. Arch Appl Mech 2012;82(12):1709-52.

[10] Niezrecki C, Brei D, Balakrishnan S, Moskalik A. Piezoelectric actuation: state of the art. Shock Vib Dig 2001;33(4):269-80.

[11] Zhu XH, Meng ZY. Operational principle, fabrication and displacement characteristic of a functionally gradient piezoelectric ceramic actuator. Sens Actuators A 1995;48:69-76.

[12] Wu CCM, Kahn M, Moy W. Piezoelectric ceramics with functional gradients: a new application in material design. J Am Ceram Soc 1996;79:809-12.

[13] Lim CW, He LH. Exact solution of a compositionally graded piezoelectric layer under uniform stretch, bending and twisting. Int J Mech Sci 2001;43:2479-92.

[14] Reddy JN, Cheng ZQ. Three-dimensional solutions of smart functionally graded plates. ASME J Appl Mech 2001;68:234-41.

[15] Zhong Z, Shang ET. Three-dimensional exact analysis of a simply supported functionally gradient piezoelectric plate. Int J Solids Struct 2003;40:5335-52.

[16] Lu P, Lee HP, Lu C. An exact solution for functionally graded piezoelectric laminates in cylindrical bending. Int J Mech Sci 2005;47:437-58.

[17] Lu P, Lee HP, Lu C. Exact solutions for simply supported functionally graded piezoelectric laminates by Stroh-like formalism. Comput Struct 2006;72:352-63.

[18] Liu TT, Shi ZF. Bending behavior of functionally gradient piezoelectric cantilever. Ferroelectrics 2004;308:43-51.

[19] Shi ZF, Chen Y. Functionally graded piezoelectric cantilever beam under load. Arch Appl Mech 2004;74:237-47.

[20] Xiang HJ, Shi ZF. Static analysis for functionally graded piezoelectric actuators or sensors under a combined electro-thermal load. Eur J Mech A Solids 2009;28:338-46.

[21] Yang L, Zhifei S. Free vibration of a functionally graded piezoelectric beam via state-space based differential quadrature. Compos Struct 2009;87:257-64.

[22] Liu GR, Tani J. Surface waves in functionally gradient piezoelectric plates. ASME J Vib Acoust 1994;116:440-8.

[23] Chen WQ Ding HJ. On free vibration of a functionally graded piezoelectric rectangular plate. Acta Mech 2002;153:207-16.

[24] Lee HJ. Layerwise laminate analysis of functionally graded piezoelectric bimorph beams. J Intell Mater Syst Struct 2005;16:365-71.

[25] Yang J, Xiang HJ. Thermo-electro-mechanical characteristics of functionally graded piezoelectric actuators. Smart Mater Struct 2007;16:784-97.

[26] Behjat B, Salehi M, Sadighi M, Armin A, Abbasi M. Static, dynamic, and free vibration analysis of functionally graded piezoelectric panels using finite element method. J Intell Mater Syst Struct 2009;20:1635-46.

[27] Behjat B, Salehi M, Armin A, Sadighi M, Abbasi M. Static and dynamic analysis of functionally graded piezoelectric plates under mechanical and electrical loading. Scientia Iranica Trans B: Mech Eng 2011;18(4):986-94.

[28] Doroushi A, Eslami MR, Komeili A. Vibration analysis and transient response of an FGPM Beam under thermo-electro-mechanical loads using higher-order shear deformation theory. J Intell Mater Syst Struct 2011;22:231-43.

[29] $\mathrm{Wu} \mathrm{XH}$, Chen CQ, Shen YP. A high order theory for functionally graded piezoelectric shells. Int J Solids Struct 2002;39:5325-44.

[30] Touratier M. An efficient standard plate theory. Int J Eng Sci 1991;29:901-16.

[31] Polit O, Touratier M. High-order triangular sandwich plate finite element for linear and non-linear analyses. Comput Meth Appl Mech Eng 2000;185(24):305-24.

[32] Dau F, Polit O, Touratier M. An efficient C1 finite element with continuity requirements for multilayered/sandwich shell structures. Comput Struct 2004;82:1889-99.

[33] Ossadzow-David C, Touratier M. A multilayered piezoelectric shell theory. Compos Sci Technol 2004;64:2121-37.

[34] Fernandes A, Pouget J. Analytical and numerical approaches to piezoelectric bimorph. Int J Solids Struct 2003;40:4331-52.

[35] Vidal P, Polit O. A family of sinus finite elements for the analysis of rectangular laminated beams. Compos Struct 2008;84:56-72.

[36] Vidal P, Polit O. A refined sine-based finite element with transverse normal deformation for the analysis of laminated beams under thermomechanical loads. J Mech Mater Struct 2009;4(6):1127-55.

[37] Benjeddou A. Advances in piezoelectric finite element modeling of adaptive structural elements: a survey. Comput Struct 2000;76:347-63.

[38] Annigeri AR, Ganesan N, Swarnamani S. Free vibration behavior of multiphase and layered magneto-electro-elastic beam. J Sound Vib 2007:299(1-2):44-63.

[39] Marcus MA. Performance characteristics of piezoelectric polymer flexure mode devices. Ferroelectrics 1984;57:203-20.

[40] Takagi K, Li JF, Yokoyama S, Watanabe R, Almajid A, Taya M. Design and fabrication of functionally graded PZT/Pt piezoelectric bimorph actuators. Sci Technol Adv Mater 2002;3:217-24. 